PROF. SÍLVIA CALDEIRA (Orcid ID : 0000-0002-9804-2297)

DR. VIVIENNE BRADY (Orcid ID : 0000-0001-9996-3269)

PROF. FIONA TIMMINS (Orcid ID : 0000-0002-7233-9412)

Received Date : 11-Sep-2016

Revised Date : 13-Feb-2017

Accepted Date : 12-Mar-2017

Article type : Review

Article Title: Spiritual aspects of living with infertility: synthesis of qualitative studies

\title{
Authors information:
}

Joana Romeiro, PhD Student, MSc, PGDipPN, RN

Institute of Health Sciences, Universidade Católica Portuguesa, Portugal. E-mail: joana.m.romeiro@gmail.com

Sílvia Caldeira, $\mathrm{PhD}$, MSc Bioethics, PGDipPN, RN

Institute of Health Sciences, Universidade Católica Portuguesa, Portugal. E-mail: scaldeira@ics.lisboa.ucp.pt.

Vivienne Brady, PhD, RM, RGN, RNT, MSc, Midwifery BSc (Hons), Assistant Professor in Midwifery

Assistant professor at School of Nursing and Midwifery, Trinity College Dublin, Ireland. E-mail: bradyvi@tcd.ie

Fiona Timmins, PhD, MSC, MA, FFNRCSI, BNS, BSc, Health \& Soc (Open), BA (Open), RNT, RGN

Associate professor at School of Nursing and Midwifery, Trinity College Dublin, Ireland. E-mail: timminsf@tcd.ie

Jenny Hall, EdD, MSc, RM, ADM, PgDip(HE)

This article has been accepted for publication and undergone full peer review but has not been through the copyediting, typesetting, pagination and proofreading process, which may lead to differences between this version and the Version of Record. Please cite this article as doi: $10.1111 /$ jocn. 13813

This article is protected by copyright. All rights reserved. 
Centre of Midwifery, Maternal and Perinatal Health and Faculty of Health and Social Sciences,

Bournemouth University, UK.

E-mail: jhall1@bournemouth.ac.uk

\section{Author for correspondence:}

Sílvia Caldeira

scaldeira@ics.lisboa.ucp.pt

Instituto de Ciências da Saúde

Edifício da Biblioteca João Paulo II- $5^{\circ}$ piso

Gabinete n. 4561

Palma de Cima

1649-023 Lisboa

Tel: 00351217225075

Sources of support: The authors report no grants or funding sources were provided to the submitted article.

Conflict of interest: None to declare

Spiritual as pects of living with infertility: a synthes is of qualitative studies

\section{ABSTRACT}

Aim: To identify the spiritual aspects of patients experiencing infertility and seek a deeper and broader meaning of the involuntary childlessness experience.

Background: Infertility can be the cause for a spiritual cris is among some couples. Those who endure this involuntary childlessness condition frequently experience contradictory feelings and needs. In this context, core aspects of spirituality such as meaning and purpose in life are often questioned.

This article is protected by copyright. All rights reserved. 
Design: A review and synthesis of qualitative empirical research was undertaken in order to seek a deeper understanding of the spiritual aspects of patients' experiences of infertility.

Methods: An aggregative synthesis was conducted according to Saini \& Shlonsky (2012), using thematic analysis.

Results: A total of 26 studies included female, male and couples. Settings revealed interviewees in different infertility phases such as diagnosis, Assisted Reproductive Technologies (ARTs) and following fertility treatments. Two main themes emerged: spiritual needs and spirituality as a coping resource for infertility.

Conclusion: Infertility affects the holistic existence of the couples. This adversity awakens spiritual needs along with unmet needs of parenthood. Coping strategies incorporating spirituality can enhance the ability of couples to overcome childlessness and suffering.

Relevance to clinical practice: Infertile couples' experiences of infertility may offer an opportunity for spiritual care particularly related to the assessment of spiritual needs and the promotion of spiritual coping strategies. Effective holistic care should support couples in overcoming and finding meaning in this life and health condition.

Keywords: Holistic care, fertility, midw ifery, nursing, spirituality.

What does this paper contribute to the wider global clinical community?

- Spiritua lity is a mean to adapt to infertility.

- Infertility awakens spiritual needs along with unmet needs of parenthood.

- Nurses and midwives are in a privileged position to provide support and spiritual care in fertility health care contexts.

This article is protected by copyright. All rights reserved. 


\section{INTRODUCTION}

Infertility is globally regarded as a disabling issue affecting public health (Centers for Disease Control and Prevention 2014). The defining concepts have evolved over time with inconsistent understandings arising among a variety of disciplines (Gurunath, Pandian, Anderson \& Bhattacharya 2011). Nevertheless emergent definitions agree that infertility is a health reproductive disability that limits in a longer or shorter period of time the ability to conceive, to carry a pregnancy and to successfully give birth to a biological child (Gurunath et al. 2011). After the International Committee for Monitoring Assisted Reproductive Technology (ICMART) and the World Health Organization (WHO) have revised the terminology (Zegers-Hochschild et al. 2009), infertility is defined as the inability to conceive and have a successful pregnancy after 12 months without contraception and having regular sexual intercourse. Two types of infertility are recognised. Primary infertility is described as the inability to conceive, carry a pregnancy or have a live birth without ever before having had a living child. In contrast, secondary infertility occurs when the inability to conceive carry a pregnancy or have a live birth happens when there has already been a living child (WHO 2016).

A broad study conducted by the WHO across 190 countries revealed the real magnitude of this health issue after $1.9 \%$ of the 277 surveyed women, with ages between 20 and 44 years old be ing diagnosed with primary infertility (Mascarenhas, Flaxman, Boerma, Vanderpoel \& Stevens 2012). At the same time, women who had already one living child have experienced an inability to conceive in $10.5 \%$ of the reported cases. Additionally, 48.5 million couples were reported as having difficulties in getting pregnant in 2010 (Mascarenhas et al. 2012). The decreasing numbers of births per women in the subsequent years to this systematic analys is (from 2.5 children in 2010-2015 to 2.0 children in 20952100), and the increasing rates of childlessness, have both evoked concerns towards the future of the next generation (United Nations 2015).

The origins of infertility are not only biological or physical (gynaecological or reproductive and sexual transmitted diseases) but also related to exposure to environmental, chemical or occupational conditions (Centers for Disease Control and Prevention 2014). In 40\% of cases, both female and male factors are implicated in the couple's infertility (NICE 2013). Unknown causes are also acknowledged in 30\% of the situations (Centers for Disease Control and Prevention 2014).

This article is protected by copyright. All rights reserved. 
Global advances in Assisted Reproductive Technology (ART) have translated into the development of fertility services, enabling couples to seek help in conceiving through resourceful techniques and medical treatments such as in vitro fertilization (IVF), egg donation, sperm donation, intracytoplasmic sperm injection (ICSI), and embryo donation (Allot, Payne \& Dann 2013).

The fulfilment of the couple's wish of having a bloodline family is associated with actively seeking complex and invasive medical treatments (Allot et al. 2013). In this context men and women endure long and lasting psychological and emotional strain not only with the diagnosis process but also with treatment cycles and its adverse effects (Oddens, Tonkelaar \& Nieuwenhuyse 1999). This situation impacts on both partners (Pasch \& Dunkel-Schetter 1997). Overall, women experiencing infertility manifest greater emotional distress (Oddens et al. 1999) and a lower quality of life and well-being compared with women who conceive naturally (McQuillan Stone \& Greil 2007, Oddens et al. 1999). Findings related to involuntary childlessness have revealed it to be an adverse life event with severe emotional and physical consequences (Oddens et al. 1999) capable of triggering spiritual needs and questioning the purpose and meaning of life. Although spirituality is becoming a growing theme of study in nursing literature, the assessment when caring for infertile patients is still poorly developed (Roudsari, Allan \& Smith 2007).

Spirituality is acknowledged as a complex and dynamic concept capable of changing over time and cultures and therefore difficult to measure and define (Weathers, McCarthy \& Coffey 2016). It is considered as "a way of being in the world in which a person feels a sense of connectedness to self, others, and/or a higher power or nature; a sense of meaning in life; and transcendence beyond self, everyday living, and suffering" (Weathers et al. 2016, p.93). Connectedness (with self, with others, with the environment), transcendence and meaning in life have been described as essential attributes to the concept (Weathers et al. 2016). Although some authors have defined its characteristics and attributes (Caldeira, Carvalho \& Vieira 2013, Weathers et al. 2016) misconception has led to the interchangeable use of concepts such as spirituality and religiosity. The relationship between both is recognised, however religious beliefs and practices are identified as manifestations of one's spiritual existence and a dimension of spirituality (Weathers et al. 2016). Spirituality is part of a holistic 
experience, particularly in times of crisis and illness (Caldeira et al. 2013, Hatamipour, Rassouli, Yaghmaie, Zendedel \& Alavi Majd 2015, Weathers et al. 2016).

In relation to infertility, couples often resort to the use of coping strategies to deal with the effects of treatment and imposed childlessness in order to find new meaning and purpose in life. Therefore, it is essential to assess and support the spiritual coping of both individuals and couples (Pasch \& DunkelSchetter 1997). For example, cultural and religious practice have been identified as a resource to support transcendence through suffering (Weathers et al. 2016).

The need to design protocols to address psychosocial needs has been recognised in midwifery and in nursing practice with additional steps also being taken towards the recognition of spiritual beliefs, and with the potential for psychological interventions (Andrews 2013). Early findings have already established a connection between infertility and religious beliefs (McQuillan et al. 2007, Roudsari et al. 2007). For instance, religious practice was associated with increased life satisfaction (McQuillan et al. 2007), and prayer was identified as a way to overcome suffering in infertile women (Roudsari et al. 2007). However, the literature lacks confirmatory evidence that spirituality and/or religiosity offer potentially positive coping strategies for couples. Calls for nursing research have been made to address this gap to identify the known attributes of spirituality and to review the empirical research, with the focus on qualitative studies in different samples and settings to ascertain potential pos itive benefits or associations (Weathers et al. 2016). This idea is reinforced by the need for funding to be made available for nursing research in ART (Allan 2013) and concerning spiritual care in particular (Roudsari et al. 2007).

\footnotetext{
AIMS

This review aims to identify the spiritual needs of individuals experiencing infertility and seek a deeper and broader meaning of the involuntary childlessness experience. Findings from qualitative evidence will help nurses and midwives as well as other health care professionals to acknowledge the relevance of effective holistic care. This study will provide the foundations for contextualized intervention and the development of an approach capable of enhancing the ability of individuals and couples to cope efficiently with adversity.
}

This article is protected by copyright. All rights reserved. 


\section{METHODS}

An aggregative synthesis (Saini \& Shlonsky 2012) was conducted, after a search in July 2015. This method enabled a synthes is of the qualitative evidence with the use of thematic analysis. Common themes emerged from the findings and promoted an in-depth understanding of the spiritual aspects and needs of couples living with infertility. The literature search was conducted across five scientific databases including PsycINFO, ATLA, Cumulative Index of Nursing and Allied Health Literature (CINAHL), PubMed and Maternity and Infant Care. The databases were specifically related to the aim of this review. The PsycINFO findings enabled the researchers to include studies addressing psychological aspects but also to consider the spiritual connotations. ATLA Religion Database is a theological database that was accessed in order to capture research related to spirituality, spiritual needs and religiosity in this specific population. Maternity and Infant Care was searched in order to identify studies related to infertility. CINHAL and PubMed search was directed to find specific evidence in nursing, midwifery and medical disc iplines.

Search terms (with truncation) were used according to each database and were selected according to participants, exposure, outcomes and study type (Table 1). The term spirituality was not included in the search strategy, as this was found to narrow the search in previous exploratory searches, and could increase the probability of missing valuable citations.

\section{Table 1 - Search terms.}

The search was run with no date or geographical limits. Studies considered eligible for inclus ion were published in peer-reviewed journals in English, Spanish or Portuguese. Papers focusing experiences of involuntary childlessness of men, women, both genders, or couple were included. For the same purpose, studies were considered eligible when the biomedical definition of infertility was recognised, whether in its primary or secondary form (Zegers-Hochschild et al. 2009). Spirituality aspects were based on the concept of Weathers et al. (2016), namely the following attributes of connectedness (self, others, God or superior being and the world) transcendence and the meaning of life. Spiritual needs were assessed based on Narayanasamy (Narayanasamy 2010) and McSherry and Smith (McSherry \& Smith 2012) research, which lists the need for meaning and purpose, need for love and harmonious

This article is protected by copyright. All rights reserved. 
relationships, need for forgiveness, need for a source of hope and strength, need for trust, need for expression of personal be liefs and values, need for spiritual practices, expression of concept of God or Deity or Divinity. These needs were used to identify, to extract data and to support the analys is of the included studies.

The following were excluded: quantitative or mixed method studies, dissertations and papers that exclus ively addressed health professionals' experiences.

Initial search resulted in a total of 5404 articles of which 282 were removed as duplicates. Two independent reviewers examined the results in the next phases according to the inclusion criteria. At this stage, the remaining 5126 titles were analysed and 4570 were excluded. All 556 abstracts were read and 433 were excluded. The full texts (123) were read and 26 papers were included in the synthesis (Figure 1).

Figure 1 - Search, selection, appraisal and inclusion of the results.

The selected studies were analysed according to the Critical Appraisal Skills Programme (CASP 2013) and simultaneously to the Consolidated Criteria for Reporting Qualitative Research (COREQ) (Tong Sainsbury \& Jonathan 2007). The first tool (Table 2) assessed the articles in terms of: clear statement of the aims, appropriateness of the qualitative methodology and the research design, recruitment strategy, data collection, relationship between researchers and participants, ethical issues, rigour of data analysis, clear statement of the findings and value of the research in a 10-points score (CASP 2013). The COREQ is an instrument for reporting qualitative research comprised of 32 items and has been considered in this study to facilitate a more in-depth appraisal regarding three domains: research team and reflexivity, study design and analysis and findings (Tong et al. 2007) (Table 3). Two authors conducted the quality appraisal independently. When necessary, both researchers discussed the evaluation attributed to the qualitative evidence that could impact on its rating. According to CASP, all artic les described the aim and the value of the research. However the majority did not demonstrate adequate consideration of the relationship between researchers and participants (Table 2).

This article is protected by copyright. All rights reserved. 
Table 2- CASP (2002)

According to COREQ, the studies also lack the participants' knowledge of the interviewer $(n=21)$, the experience and training of the researchers $(n=20)$ and the description of the interviewers' characteristics $(n=20)$. When using COREQ, the majority of the studies lacked a description of the coding tree which was not identified in the CASP appraisal (Table 3).

\section{Table 3 - COREQ quality appraisal results.}

Nevertheless, no articles were excluded for low qua lity due to the importance of every finding and its contribution to the aim of this study.

Data for each study was extracted and organised in a table to describe the main characteristics and to identify the major and minor themes. Themes were illustrated in association with quotations exclus ively from the participants of the 26 included papers. This analysis required constant reading and re-reading in order to truthfully reflect the evidence and also produce a broader synthesis across all papers. Similarities and differences between studies were extracted. Two researchers conducted this stage independently and conflicts were resolved through consensual discussion.

\section{RESULTS}

All included studies (Table 4) were published from 1991 to 2015, more frequently published in 2002 $(n=3), 2009(n=3), 2011(n=3)$ and $2013(n=3)$. Nursing and Midwifery peer-reviewed journals were the main target $(n=8)$ as well as medicine $(n=7)$, social sciences $(n=5)$, psychology $(n=3)$, therapy $(n=1)$ and social work $(n=1)$. One publication was not related to any specific discipline but to a multidisc iplinary journal (Mogobe 2005).

This article is protected by copyright. All rights reserved. 


\section{Table 4 - Characte ris tics of the included studies.}

Most participants of the 26 articles were infertile women $(n=403)$, couples $(n=36)$, and infertile men $(n=34)$. Samples ranged from one (Apfel \& Keylor 2002, Seybold 2002) to 38 participants (Guntupalli \& Chenchelgudem 2004). Studies were conducted in the UK ( $n=5)$, USA ( $n=4)$, Africa $(n=4)$, Iran $(n=3)$, Australia $(n=2)$, Pakistan $(n=2)$, Portugal $(n=1)$, Israel $(n=1)$, China $(n=1)$, Italy $(\mathrm{n}=1)$, India $(\mathrm{n}=1)$ and Taiwan $(\mathrm{n}=1)$. A multinational approach was addressed in two on-line studies (Cunningham \& Cunningham 2013, Toscano \& Montgomery 2009). Two articles simultaneously presented English and Pakistani participants (Batool \& V isser 2015) and English and Iranian individuals ( Roudsari \& Allan 2011).

Phenomenology $(n=9)$ and grounded theory $(n=5)$ were the qualitative methods most used. Interviews were the main data collection method $(\mathrm{n}=23)$. These were conducted face-to-face (Apfel \& Keylor 2002, Batool \& Visser 2015, Behboodi-Moghadam Salsali Eftekhar-Ardabily Vaismoradi \& Ramezanzadeh F. 2013, Bell 2009, Benasutti 2003, Bhatti Fikree \& Khan 1999, Chen \& Landau 2015, Cipolletta \& Faccio 2013, Davis \& Dearman 1991, Dyer Abrahams Hoffman \& van der Spuy 2002, Dyer Abrahams Mokoena \& van der Spuy 2004, Guntupalli \& Chenchelgudem 2004, Lee Choi Chan \& Ng 2009, McCarthy 2008, Mogobe 2005, Mosa lanejad Parandavar Gholami \& Abdollahifard 2014, Peddie Teijlingen \& Bhattacharya 2005, Peters 2003, Peters Jackson \& Rudge 2011, Porter \& Bhattacharya 2008, Roudsari \& Allan 2011, Silva Ferreira Brito Dias \& Henriques 2012) over the telephone (Su \& Chen 2006) or on-line (Cunningham \& Cunningham 2013). Some studies combined interviews with informal notes or diaries (Roudsari \& Allan 2011, Seybold 2002), self-reflexive journal (Benasutti 2003) and observation (Guntupalli \& Chenchelgudem 2004, Seybold 2002). A public electronic media source was used in one case as the exclusive means of obtaining data (Toscano \& Montgomery 2009).

The prime locations selected to conduct face-to-face interviews were fertility centres or other health care facilities attended by couples $(n=14)$. Participants' homes $(n=5)$ were also considered a privileged context to collect data. Physical, emotional, psychosocial, spiritual, socio-economic and cultural aspects were explored in depth.

This article is protected by copyright. All rights reserved. 
Descriptions of involuntary childlessness comprised two main periods in particular endured by couples: from the diagnos is of infertility to treatment (Apfel \& Keylor 2002, Batool \& Visser 2015, Behboodi-Moghadam et al. 2013, Bell 2009, Bhatti et al. 1999, Chen \& Landau 2015, Cipolletta \& Faccio 2013, Cunningham \& Cunningham 2013, Davis \& Dearman 1991, Dyer et al. 2002 2004, Guntupalli \& Chenchelgudem 2004, Mogobe 2005, Mosalanejad et al. 2014, Porter \& Bhattacharya 2008, Roudsari \& Allan 2011, Seybold 2002, Silva et al. 2012, Toscano \& Montgomery 2009), and living beyond the treatment (Bell 2009, Benasutti 2003, Chen \& Landau 2015, Guntupalli \& Chenchelgudem 2004, Lee et al. 2009, McCarthy 2008, Peddie et al. 2005, Peters 2003, Peters et al. 2011, Su \& Chen 2006, Toscano \& Montgomery 2009).

Two main themes were synthetized: expression of spiritual needs and spirituality as a coping resource for infertility, both based on the themes described in each study (Table 4). The themes are presented below with extracted quotations from the original study (Table 5).

\section{Table 5 - Main themes and quotations from the original studies.}

Infertility challenged many women and men to face not only a physical but a lso a spiritual journey in order to achieve the goal of having a child. Indeed, the majority of the participants faced hardship when dealing with this life event (Batool \& Visser 2015, Bell 2009, Bhatti et al. 1999, Chen \& Landau 2015, Cipolletta \& Faccio 2013, Davis \& Dearman 1991, Dyer et al. 2002, McCarthy 2008, Mogobe 2005, Mosalanejad et al. 2014, Peddie et al. 2005, Peters 2003, Peters et al. 2011, Toscano \& Montgomery 2009). Coping strategies aiming to adapt and transcend suffering included the development of resilience (Lee et al. 2009, Peters et al. 2011) and maintaining or regaining hope (Bhatti et al. 1999, Cipolletta \& Faccio 2013, Davis \& Dearman 1991, Lee et al. 2009, Mosalanejad et al. 2014, Peddie et al. 2005, Porter \& Bhattacharya 2008, Toscano \& Montgomery 2009).

This article is protected by copyright. All rights reserved. 


\section{DISCUSSION}

This review focused on synthesising the outcomes from qualitative research concerning spiritual aspects of couples living with infertility. In general, results of this review are in line with literature, which links infertility and spirituality. Nevertheless, specific data was still found to be limited. Overall infertility was perceived as a condition that affected the couple's existence on a holistic level. One of the core findings revealed that physical, emotional, psychological, social and spiritual dimensions of the individual underwent several changes due to this living experience. Previous qualitative and quantitative studies have focused on psychosocial aspects (Greil, Slauson-Blevins \& McQuillan 2010, Oddens et al. 1999). In addition, a growing body of nursing and midwifery literature has acknowledged the significance of the spiritual dimension in reproductive care (Roudsari et al. 2007). Therefore this study exceeded the existing evidence giving a new insight into the spiritual assessment of infertile couples.

This research identified meaning of life, connectedness to self, to others and beyond as characteristics of the couple's experience of childlessness, in line with the recent analysis of the concept of spirituality (Weathers et al., 2016). Individuals who are not religious perceive themselves as spiritual beings (Weathers et al., 2016) and similarly this study found that, whether addressing religion or not, the couples frequently had a transcendent discourse when analysing the quotations (Benasutti, 2003; McCarthy, 2008; Roudsari and Allan, 2011; Toscano and Montgomery, 2009). Attributes of spirituality (Weathers et al., 2016) were clearly present, despite the stage each infertile individual reported to be in. Interestingly, spirituality is still considered a poorly explored field in this healthcare context (Roudsari et al. 2007). Nevertheless, meaning in life for couples appeared to be defied in this study by unsuccessful conception, pregnancy and birth of a biological child. Furthermore, an eager wish to become a parent and undergo the transitional process was an expected outcome of adulthood and marriage (Batool \& V isser 2015, Cunningham \& Cunningham 2013, Dyer et al. 2004, Mogobe 2005, Silva et al. 2012). This finding is consistent with other researchers statements of how motherhood is important as a transition in making existential meaning (Prinds, Hvidt, Mogensen \& Buus 2013). Self-identity based on men and women's assumptions of future parenthood faded away when individuals acknowledged themselves as being reproductively impaired (Seybold 2002).

This article is protected by copyright. All rights reserved. 
Barriers in conceiving and reaching the goal of parenthood proved to influence the values, the identity and the beliefs of the couple, and so, meaning in life is reappraised by resisting the previous purpose of their existence (Peters 2003). Early research reported that females who did not perceive infertility as a disability had a higher life satisfaction score in comparison to fertile women (McQuillan et al. 2007). Satisfaction seems to be connected to meaning of life and to the significance that individuals attribute to the ir goals in life (Park 2016). The construction of a new meaning is not accepted from the beginning. These findings could expla in why in this review couples are not willing to give up without a struggle engaging in an intense pursuit of all possible methods to achieve their desire to have a child (Cipolletta \& Faccio 2013, Porter \& Bhattacharya 2008). The awareness of infertility manifests itself in self-questioning (Peters 2003) and engaging in medical and traditional treatments. Individuals perceive this as the only purpose in life and they deeply transform their existence through changes in daily routines (Bell 2009, Cunningham \& Cunningham 2013, Peters 2003, Porter \& Bhattacharya 2008) to enhance reproduction probabilities (Bell 2009, Cunningham \& Cunningham 2013, Peters 2003, Porter \& Bhattacharya 2008).

In other words, infertility appeared to be a synonym of treatment and translated into active pursuit of a cure. This situation was culturally determined by the underlying beliefs and meanings that prevailed in the couple's social background. Social role fulfilment had a close relationship with motherhood and fatherhood, with recognised consequences to self and to community survival in developing countries (Batool \& Visser 2015, Cunningham \& Cunningham 2013, Dyer et al. 2002, Mogobe 2005, Silva et al. 2012). The search for the ultimate purpose in life with the additional social pressure evoked suffering. Therefore this review has provided insight to what other authors had stated towards spiritual distress and the unfulfilled spiritual needs (Caldeira et al. 2013). As far as it could be determined, these findings contribute to making a clear connection between the experience of living with infertility and the spiritual needs as defined before (McSherry \& Smith 2012, Narayanasamy 2010). A spiritual crisis was proven to arouse in waves of hope and despair lived by men and women during fertility cycles (Bhatti et al. 1999, Cipolletta \& Faccio 2013, Mosalanejad et al. 2014, Peddie et al. 2005). The waiting that precedes treatment results is a period of great anxiety and expectation followed in most cases by disappointment due to an unsuccessful pregnancy. This psychological 
roller-coaster has been early described (Dyer 2010, McQuillan et al. 2007, Oddens et al. 1999), and was in line with the emotions and feelings reported in this review. For instance, pain (BehboodiMoghadam et al. 2013, Benasutti 2003, Chen \& Landau 2015, Davis \& Dearman 1991, Lee et al. 2009, Mogobe 2005, Su \& Chen 2006, Toscano \& Montgomery 2009), stress (Benasutti 2003, Mosalanejad et al. 2014, Peddie et al. 2005, Su \& Chen 2006, Toscano \& Montgomery 2009) and anxiety (Batool \& Visser 2015, Chen \& Landau 2015, Cipolletta \& Faccio 2013, Lee et al. 2009, Toscano \& Montgomery 2009). Similar to cancer patients (Ferrel, Taylor, Sattler, Fowler \& Cheyney 1993), pa in in involuntarily childlessness is associated with the acknowledgement of a disease capable of triggering one's sense of loss, loss of control and helplessness (Cunningham \& Cunningham 2013, Davis \& Dearman 1991, Toscano \& Montgomery 2009). Immediate effects were not only manifested phys ically but also in self-identity (Batool \& Visser 2015, Behboodi-Moghadam et al. 2013, Benasutti 2003, Cunningham \& Cunningham 2013, Dyer et al. 2002, 2004, Lee et al. 2009, Mogobe 2005, Mosalanejad et al. 2014, Peddie et al. 2005, Silva et al. 2012, Su \& Chen 2006, Toscano \& Montgomery 2009). The intensive physical, emotional and spiritual endurance is such that awakens a sense of powerlessness. Early literature addresses the connection of pain with perceived illness and spiritual well-being helping to understand why in some cases individuals decided to cease fertility care to regain control over their life (Ferrel et al. 1993).

Spiritual distress and spiritual needs have been reported as a fading away with time, and remain until after the birth of a child or in times of making the decision to end the treatment (Bell 2009, Lee et al. 2009, McCarthy 2008, Peddie et al. 2005 2005, Su \& Chen 2006, Toscano \& Montgomery 2009). Physical timing did not seem to correspond with spiritual readiness. The biological and ideal age to conceive did not match the timeframes established by couples to reach their parental goal (Chen \& Landau 2015, Cunningham \& Cunningham 2013, Toscano \& Montgomery 2009). This contradictory outcome was also mentioned by other scholars (Locke \& Budds 2013). Although some women reported being ready to become a mother as soon as they got married reproductive conditioning was a barrier (Dyer et al. 2004). In addition, it is known that delayed motherhood and advanced age decrease fertility along with the ability to naturally conceive (Dunson, Baird \& Colombo 2004). The loss of the ability to plan the future induced participants' resentment towards the self in addition to a

This article is protected by copyright. All rights reserved. 
sense of failure (Batool \& Visser 2015, Behboodi-Moghadam et al. 2013, Benasutti 2003, Cunningham \& Cunningham 2013, Dyer et al. 2002 2004, Lee et al. 2009, Mogobe 2005, Mosalanejad et al. 2014, Peddie et al. 2005, Silva et al. 2012, Su \& Chen 2006, Toscano \& Montgomery 2009). Grief was perceived over the loss of the hope for child and all the related experiences of pregnancy, labour and parenting (Apfel \& Keylor 2002, McCarthy 2008, Toscano \& Montgomery 2009). This was described as a traumatic process (Peddie et al. 2005) and infertile women expressed the need to be spiritually supported.

Transformative spiritual learning is proven to be triggered by adversity but with different implications when compared to fertile couples (Klobucar 2016). These assumptions are also presented in this review as individuals' self-references were necessarily transformed, inducing them to reframe their self-existence. Coping strategies to overcome this vulnerable phase were described as the search for western medicine or traditional practices (Bhatti et al. 1999, Dyer et al. 2004, Lee et al. 2009, Mogobe 2005, Peters 2003, Porter \& Bhattacharya 2008). Also alternative strategies of fulfilling parenthood, such as adoption, taking care of others or remaining childless were found (Batool \& Visser 2015, Bell 2009, Benasutti 2003, Bhatti et al. 1999, Lee et al. 2009, Mogobe 2005, Peddie et al. 2005, Toscano \& Montgomery 2009). The identified need for inner meaning was intrinsic to the couple's relationship despite the outcomes of the infertility experience, as every human being needs to find meaning in life that may guide the sense of self existence (Park 2016).

Connectedness as a spiritual attribute (Weathers et al. 2016) was closely related to a sense of failure by carrying infertility or postponing motherhood (Chen \& Landau 2015, Cunningham \& Cunningham 2013, Toscano \& Montgomery 2009). Partners often remain the main support to each other (Greil et al. 2010). The closeness felt between partners helped to deal with and adjust to the diagnosis and treatments (Batool \& Visser 2015, Benasutti 2003, Bhatti et al. 1999, Davis \& Dearman 1991, Dyer et al. 2002 2004, Lee et al. 2009, Peters et al. 2011, Toscano \& Montgomery 2009), as adverse events have proven not to transform or redefine but to enhance the marital relationship that already existed (Greil et al. 2010). Furthermore, current results suggest that if a partnership was already vulnerable involuntarily childlessness mixed with cultural influences may quickly induce individual affairs, polygamy or divorce (Behboodi-Moghadam et al. 2013, Benasutti 2003, Bhatti et al. 1999, Chen \& 
Landau 2015, Dyer et al. 2002 2004, Guntupa lli \& Chenchelgudem 2004). These findings contribute to the existing evidence that associates intimate partner violence with infertility and subfertility in low and middle income countries (Stellar, Garcia-Moreno, Temmerman \& Poel 2015). However, although domestic violence emerged from women in the included studies it was not always acknowledged (Behboodi-Moghadam et al. 2013, Bhatti et al. 1999, Dyer et al. 2002). Emotional and physical abuse from the partner and extended family (Batool \& V isser 2015, Behboodi-Moghadam et al. 2013, Chen \& Landau 2015, Dyer et al. 2002 2004, Guntupalli \& Chenchelgudem 2004, Toscano \& Montgomery 2009) made women spiritually vulnerable without the support, the love and the harmonious relationships they needed to achieve a state of spiritual well-being (Mahajan et al. 2009). Furthermore, the social displacement and self-disconnection from family, friends and other pregnant couples led to isolation (Batool \& Visser 2015, Behboodi-Moghadam et al. 2013, Bhatti et al. 1999, Davis \& Dearman 1991, Dyer et al. 2002, Peddie et al. 2005, Peters 2003, Peters et al. 2011, Toscano \& Montgomery 2009).

A close relationship between dissatisfaction with the infertility care provided and the healthcare professionals' lack of assessment of spiritual needs was recognised and perpetuated in defective interventions (Lee et al. 2009, McCarthy 2008, Mogobe 2005, Mosalanejad et al. 2014, Roudsari \& Allan 2011). This concurs with the previous described gap in patient-centred care in infertility services (van Empel et al. 2010). The need to be understood (Davis \& Dearman 1991) and supported (Silva et al. 2012) was well documented, in this review, in all phases of involuntary childlessness, from the diagnos is, through treatment and beyond (Cunningham \& Cunningham 2013). Even though, formal counselling based on emotional and psychological assessment was determined by healthcare professionals, spiritual and religious support was most valued by infertile couples (Roudsari \& Allan 2011) and a core finding in this study.

The transcendence from suffering to a state of satisfaction and spiritual well-being reflected the effective use of coping strategies. Overcoming spiritual distress was often achieved by a positive approach, proactiveness, acceptance, emotional strategies and religious strategies, which are core strategies of coping. For example, prayer was considered a religious practice closely related to spirituality that exercised a positive influence on individuals' health and well-be ing (Simão, Calde ira

This article is protected by copyright. All rights reserved. 
\& Carvalho 2016). Moreover, in this study, prayer was reported in the narratives of the participants and is considered an important aid in the adjustment to being childless, to rega ining hope and feeling empowered by connecting with a higher power (Batool \& Visser 2015, Benasutti 2003, Mogobe 2005, Mosalanejad et al. 2014, Roudsari \& Allan 2011, Toscano \& Montgomery 2009).

\section{CONCLUSION}

Spirituality and spiritual needs are clearly manifested by many individuals experiencing involuntarily childlessness, although not always recognised. This synthesis highlights its contribution to the understanding of this phenomenon by identifying expressions of spiritual needs and spirituality as a coping strategy in the circumstance of living with infertility. The analys is provided a clear connection between infertility and spirituality, but specific data was still found to be limited.

Some innovative outcomes have been identified in this synthesis, but considering some limitations, caution is needed when making conclus ions. Firstly, the small number of interviewees, the differences in age and marital status, and the inclusion of different qualitative study designs in this synthesis may compromise the transferability of the findings. In addition, us ing fertility clinics' assessments to select participants was also recognised in previous studies as a possible bias due to the fact that this population might only be composed of individuals with financial resources to access these facilities. Also, the large number of studies included women and few included couples or men. Those results are not surprising and reaffirm frequent concerns towards the feminine gender experience. Although in general terms women seemed to endure more when compared to men, it is suggested that both genders are equally affected, in psychological and social dimensions. Despite knowing that these individuals are living a long journey, only one study was based on a longitudinal approach, and these findings underline the remaining gap of how this experience evolves through time.

This article is protected by copyright. All rights reserved. 


\section{RELEVANCE TO CLINICAL PRACTICE}

Despite the limitations, these findings constitute a valuable contribution in understanding the experience of those living with infertility in a broader and holistic sense. A longitudinal approach of this dimension would enable new insight towards the progression of the spiritual journey in couples facing this adverse event. Exploration of the way in which each gender evolves and transcends suffering could also be interesting for the development of the knowledge about this phenomenon.

It is acknow ledged that there is a lack of empirical studies in literature that analyse infertility through a spiritual perspective and this gap could be transformed in an opportunity to improve research and to provide evidence-based practice and patient centred care in nursing and midwifery education and training aimed at the development of effective holistic approaches in a fertility care context, strictly related to the meaning of life.

\section{REFERENCES}

Allan H T (2013) The anxiety of infertility: the role of the nurses in the fertility clinic. Human Fertility 16, 1721.

Allot L, Payne D \& Dann L (2013) Midwifery and Assisted Reproductive Technologies. New Zealand College of Midwives 47, 10-13.

Andrews SL (2013) Psychological effects of spiritually integrated therapy for infertile women. The University of Alabama at Birmingham, Alabama, Available at: http://www.mhsl.uab.edu/dt/2015r/Andrews_uab_0005D_11012.pdf (accessed 20 May 2016).

Apfel RJ \& Keylor RG (2002) Psychoanalysis and Infertility Myths and Realities. International Journal of Psychoanalysis 83, 85-104.

Batool SS \& Visser RO (2015) Experiences of Infertility in British and Pakistani Women: A Cross-Cultural Qualitative Analysis. Health Care for Women International 37, 180-196.

Behboodi-Moghadam Z, Salsali M, Eftekhar-Ardabily H, Vais moradi M \& Ramezanzadeh F (2013) Experiences of infertility through the lens of Iranian infertile women: A qualitative study. Japan Journal of Nursing Science 10, 41-46.

Bell AV (2009) "It's way out of my league ": Low-income Women's Experiences of Medicalized Infertility. Gender and Society 23, 688-709.

This article is protected by copyright. All rights reserved. 
Benasutti RD (2003) Infertility: Experiences and Meanings. Journal of Couple \& Relationship Therapy 2, 5171.

Bhatti LI, Fikree FF \& Khan A (1999) The quest of infertile wo men in squatter settlements of Karachi, Pakistan: a qualitative study. Social Science \& Medicine 49, 637-649.

Caldeira S, Carvalho EC \& Vieira M (2013) Spiritual Distress-Proposing a New Definition and Defining Characteristics. International Journal of Nursing Knowledge 24, 77-84.

CASP (2013) Critical Appraisal Skills Programme Available at: http://www.casp-uk.net/\#!checklists/cb36 (accessed 15 January 2016).

Centers for Disease Control and Prevention (2014) National Public Health Action Plan for the Detection, Prevention, and Management of Infertility. U.S. Department of Health and Human Services. Retrieved from U.S. Department of Health and Human Services.

Chen W \& Landau R (2015) First Childbirth and Motherhood at Post Natural Fertile Age: A Persistent and Intergenerational Experience of Personal and Social Anomaly? Social Work in Health Care 54, 16-32.

Chen W \& Landau R (2015) First Childbirth and Motherhood at Post Natural Fertile Age: A persistente and intergenerational experience of personal and social anomaly? Social Work in Health Care 54, 16-32.

Cipolletta S \& Faccio E (2013) Time experience during the assisted reproductive journey: a phenomenological analysis of Italian couples' narratives. Journal of Reproductive and Infant Psychology 31, 285-298.

Collins A, Freeman EW, Boxer AS \& Tureck R (1992) Perceptions of infertility and treatment stress in females as compared with males entering in vitro fertilization treatment. Fertility and Sterility 57, 350-356.

Cunningham N \& Cunningham T (2013) Women's experiences of infertility - towards a relational model of care. Journal of Clinical Nursing 22, 3428-3437.

Davis DC \& Dearman CN (1991). Coping strategies of infertile wo men. JOGNN 20, 221-228.

Dunson D, Baird D \& Colombo B (2004) Increased infertility with age in men and women. Obstetrics and Gynecology 103, 51-56.

Dyer B (2010) Loss of - what? Grieving infertility. MIDIRS Midwifery Digest 20, 305-309.

Dyer SJ, Abrahams N, Hoffman M \& van der Spuy ZM (2002) "Men leave me as I cannot have children": wo men's experiences witj involuntary child lessness. Human Reproduction 17, 1663-1668.

Dyer SJ, Abrahams N, Mokoena NE \& van der Spuy ZM (2004)" You are a man because you have children": experiences, reproductive health knowledge and treatment-seeking behaviour among men suffering from couple infertility in South Africa. Human Reproduction 19, 960-967.

This article is protected by copyright. All rights reserved. 
Ferrel BR, Taylor EJ, Sattler GR, Fowler M \& Cheyney BL (1993) Searching for the meaning of pain. Cancer Practice 1, 185-194.

Greil AL, Slauson-Blevins K \& McQuillan J (2010) The experience of infertility: A review of recent literature. Socioogy of Health and Illness 32, 140-162.

Guntupalli AM \& Chenchelgudem P (2004) Perceptions, causes and consequences of infertility among the Chenchu tribe of India. Journal of Reproductive and Infant Psychology 22, 249-259.

Gurunath S, Pandian Z, Anderson RA \& Bhattacharya S (2011) Defining infertility - a systematic review of prevalence studies. Human Reproduction Update 17, 575-588.

Hatamipour K, Rassouli M, Yaghmaie F, Zendedel K \& Alavi Majd H (2015) Spiritual Needs of Cancer Patients: A Qualitative Study. Indian Journal of Palliative Care 21, 61-67.

Klobucar NR (2016) The role of spirituality in transition to parenthood: qualitative research using transformative learning theory. Journal of Religion and Health 55, 1345-1358.

Lee GL, Choi WH, Chan CH, Chan CL \& Ng EH (2009) Life after unsuccess ful IVF treatment in an assisted reproduction unit: a qualitative analysis of gains through loss among Chinese persons in Hong Kong. Human Reproduction 24, 1920-1929.

Locke A \& Budds K (2013) "We thought if it's going to take two years then we need to start that now": age, infertility risk and the timing of pregnancy in older first-time mothers. Health, Risk \& Society 15, 525542.

Mahajan NN, Turnbull DA, Davies MJ, Jindal UN, Briggs NE \& Taplin JE (2009) Adjustment to infertility: the role of intrapersonal and interpersonal resources/vulnerabilities. Human Reproduction 24, 906-912.

Mascarenhas MN, Flaxman SR, Boerma T, Vanderpoel S \& Stevens GA (2012) National, Regional, and Global Trends in Infertility Prevalence Since 1990: A Systematic Analysis of 277 Health Surveys. PLOS Medicine 9, 1-12.

McCarthy MP (2008) Women's Lived Enperience of Infertility After Unsuccessful Medical Intervention. Journal of Midwifery \& Women's Health 53, 319-324.

McQuillan J, Stone RAT \& Greil AL (2007) Infertility and Life Satisfaction Among Women. Journal of Family Issues 28, 955-981.

McSherry, W., \& Smith, J. (2012). Spiritual care. In Care in Nursing - principles, values and skills (Wilfred McSherry, Robert McSherry, Roger Watson, pp. 117-131). New York: Oxford University Press.

This article is protected by copyright. All rights reserved. 
Mogobe DK (2005) Denying and Preserving Self: Batswana Women's Experiences of Infertility. Afrikan Journal of Reproductive Health 9, 26-37.

Mosalanejad L, Parandavar N, Gholami M \& Abdollahifard S (2014) Increasing and decreasing factors of hope in infertile women with failure in infertility treatment: A phenomenology study. Iran Journal of Reproductive Medicine 12, 117-124.

Narayanasamy A (2010) Recognizing spiritual needs. In Spiritual assessment in healthcare practice (Wilfred McSherry and Linda Ross, pp. 37-55). Cumbria: M\&K Publishing.

NICE (2013) Fertility, Assessment and treatment for people with fertility problems. National Institute for Health and Care Excellence.

Oddens BJ, Tonkelaar I \& Nieuwenhuyse H (1999) Psychosocial experiences in women facing fertility problems - a co mparative survey. Human Reproduction 14, 255-261.

Park CL (2016) Unresolved tensions in the study of meaning in life, Journal of Constructivist Psychology, Available at: http://www.tandfonline.com/doi/full/10.1080/10720537.2015.1119083 (accessed 20 February 2016).

Pasch LA \& Dunkel-Schetter C (1997) Fertility Problems: Complex Issues Faced by Women and Couples. In Health Care for Women: Psychological, Social, and Behavioral Influences (pp. 187-201). Washington DC, USA : A merican Psychological Association.

Peddie VL, Teijlingen E \& Bhattacharya S (2005) A qualitative study of wo men's decision-making at the end of IVF treatment. Human Reproduction 20, 1944-1951.

Peters K (2003) In pursuit of motherhood: The IVF experience. Contemporary Nurse 14, 258-270.

Peters K, Jackson D \& Rudge T (2011) Surviving the adversity of childlessness: Fostering resilience in couples. Contemporary Nurse 40, 130-140.

Porter M \& Bhattacharya S (2008) Helping themselves to get pregnant: a qualitative longitudinal study on the information-s eeking behaviour of infertile couples. Human Reproduction 23, 567-572.

Prinds C, Hvidt NC, Mogensen O \& Buus N (2013) Making existential meaning in transition to motherhood - A scoping review. Midwifery 30, 733-741.

Roudsari RL \& Allan HT (2011).Women's Experiences and Preferences in Relation to Infertility Counselling: A Multifaith Dialogue. International Journal of Fertility and Sterility 5, 158-167.

Roudsari RL, Allan HT \& Smith PA (2007) Looking at infertility through the lens of relig ion and spirituality: a review of the literature. Human Fertility 10, $141-149$.

This article is protected by copyright. All rights reserved. 
Saini M \& Shlonsky A (2012) Systematic synthesis of qualitative research. Oxford: Oxford University Press.

Seybold D (2002) Choosing Therapies: A Senegalese Woman's Experience with Infertility. Health Care for Women International 23, 540-549.

Silva IR, Ferreira AM, Brito MA, Dias NM \& Henriques, CM (2012) As vivências da mulher in fértil. Revista de Enfermagem Referência 8, 181-189.

Simão TP, Caldeira S \& Carvalho EC (2016) The effect of prayer on patients' health: systematic literature review. Religions $7,11$.

Stellar C, Garcia-Moreno C, Temmerman M \& Poel S (2015) A systematic review and narrative report of the relationship between infertility, subfertility, and intimate partner violence. International Journal of Gynecology and Obstetrics 133, 3-8.

Su T \& Chen Y (2006) Transforming Hope: The Lived Experience of Infertile Women Who Terminated Treatment After in Vitro Fertilization Failure. Journal of Nursing Research 14, 46-54.

Tong A, Sainsbury P \& Jonathan C (2007) Consolidated criteria for reporting qualitative research (COREQ): a 32-item checklist for interviews and focus groups. International Journal for Quality in Health Care 19, $349-357$.

Toscano SE \& Montgomery RM (2009) The Lived Experience of Women Pregnant (Including Preconception) Post In Vitro Fertilization Through the Lens of Virtual Communities. Health Care for Women International 30, 1014 -1036.

United Nations (2015) World Population Prospects, key findings and advance tables. Department of Economic and Social Affairs, Population Available from: http://esa.un.org/unpd/wpp/publications/files/key_findings_wpp_2015.pdf. (accessed 20 March 2016).

van Empel IW, Nelen WL, Tepe ET, van Laarhoven EA, Verhaak CM \& Kremer JA (2010) Weaknesses, strenghts and needs in fertility care accord ing to patients. Human Reproduction 25, 142-149.

Weathers E, McCarthy G \& Coffey A (2016) Concept Analysis of Spirituality: An Evolutionary Approach. Nursing Forum 51, 79-96.

WHO. (2016). Infertility definitions and terminology. Available from: http:/www.who.int/reproductivehealth/topics/infertility/defin itions/en/. (Accessed 7 April 2016).

Zegers-Hochschild F, Adamson GD, Mouzon J, Ishihara O, Mansour R, Nygren K, van der Poel E (2009) The International Committee for Monitoring Assisted Reproductive Technology (ICMART) and the World 
Health Organization (WHO) Revised Glossary on ART Terminology, 2009. Human Reproduction 24, $2683-2687$.

Table 1 - Search terms.

\begin{tabular}{ll}
\hline Participants & woman \\
& women \\
& mother* \\
& parent* \\
& couple \\
\hline Exposure & infertil* \\
\hline Outcomes & need* \\
& feeling* \\
& experience* \\
& view* \\
& perception* \\
\hline Study type & qualitative research \\
\hline
\end{tabular}

This article is protected by copyright. All rights reserved. 


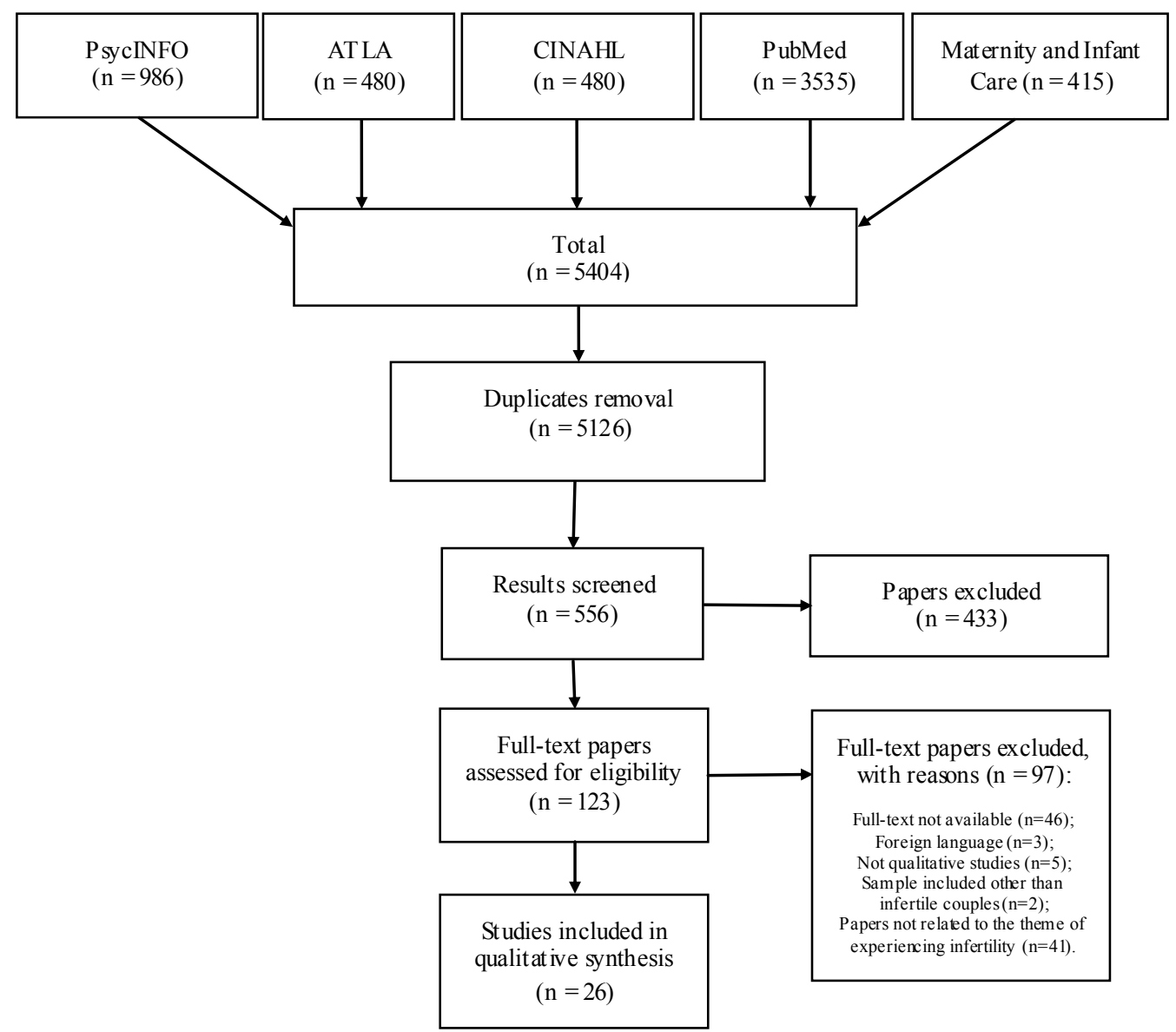

Figure 1 -Search, selection, appraisal and inclusion of the results.

This article is protected by copyright. All rights reserved. 
Table 2- CASP (2002) quality appraisal results.

\begin{tabular}{|c|c|c|c|c|c|c|c|c|c|c|c|}
\hline References & Q1 & Q2 & Q3 & Q4 & Q5 & Q6 & Q7 & Q8 & Q9 & $\begin{array}{c}\text { Q1 } \\
\text { 0 }\end{array}$ & $\begin{array}{l}\text { Final } \\
\text { score }\end{array}$ \\
\hline Apfel \& Keylor 2002 & $\mathrm{~N}$ & $\mathrm{Y}$ & CT & $\mathrm{N}$ & $\mathrm{Y}$ & $\bar{Y}$ & $\mathrm{~N}$ & $\mathrm{~N}$ & $\mathrm{~N}$ & $\bar{Y}$ & $4 / 10$ \\
\hline Batool \& Visser 2015 & $\mathrm{Y}$ & $\mathrm{Y}$ & $\mathrm{Y}$ & $\mathrm{Y}$ & $\mathrm{Y}$ & CT & $\mathrm{Y}$ & $\mathrm{Y}$ & $\mathrm{Y}$ & $\mathrm{Y}$ & $9 / 10$ \\
\hline $\begin{array}{l}\text { Behboodi-Moghadam et al. } \\
2013\end{array}$ & $\mathrm{Y}$ & $\mathrm{Y}$ & $\mathrm{Y}$ & $\mathrm{Y}$ & $\mathrm{Y}$ & $\mathrm{Y}$ & $\mathrm{Y}$ & $\mathrm{Y}$ & $\mathrm{Y}$ & $\mathrm{Y}$ & $10 / 10$ \\
\hline Bell 2009 & Y & $\mathrm{Y}$ & Y & $\mathrm{Y}$ & $\mathrm{Y}$ & CT & $\mathrm{N}$ & Y & Y & $\mathrm{Y}$ & $8 / 10$ \\
\hline Benasutti 2003 & Y & $\mathrm{Y}$ & Y & $\mathrm{Y}$ & Y & Y & Y & Y & $\mathrm{Y}$ & $\mathrm{Y}$ & $10 / 10$ \\
\hline Bhatti et al. 1999 & $\mathrm{Y}$ & $\mathrm{Y}$ & $\mathrm{Y}$ & $\mathrm{Y}$ & Y & Y & $\mathrm{Y}$ & $\mathrm{Y}$ & $\mathrm{Y}$ & $\mathrm{Y}$ & $10 / 10$ \\
\hline Chen \& Landau 2014 & Y & $\mathrm{Y}$ & Y & $\mathrm{Y}$ & Y & CT & Y & Y & $\mathrm{Y}$ & $\mathrm{Y}$ & $9 / 10$ \\
\hline Cipolletta \& Faccio 2013 & Y & $\mathrm{Y}$ & Y & $\mathrm{Y}$ & Y & CT & Y & Y & $\mathrm{Y}$ & $\mathrm{Y}$ & $9 / 10$ \\
\hline $\begin{array}{l}\text { Cunningham \& } \\
\text { Cunningham } 2013\end{array}$ & Y & $\mathrm{Y}$ & $\mathrm{Y}$ & $\mathrm{Y}$ & $\mathrm{Y}$ & CT & $\mathrm{Y}$ & $\mathrm{Y}$ & $\mathrm{Y}$ & $\mathrm{Y}$ & $9 / 10$ \\
\hline Davis \& Dearman 1991 & Y & $\mathrm{Y}$ & Y & $\mathrm{Y}$ & Y & $\mathrm{N}$ & Y & Y & Y & $\mathrm{Y}$ & $9 / 10$ \\
\hline Dyer et al. 2002 & Y & $\mathrm{Y}$ & Y & $\mathrm{Y}$ & Y & CT & Y & Y & $\mathrm{Y}$ & $\mathrm{Y}$ & $9 / 10$ \\
\hline Dyer et al. 2004 & Y & $\mathrm{Y}$ & Y & $\mathrm{Y}$ & Y & CT & Y & Y & $\mathrm{Y}$ & $\mathrm{Y}$ & $9 / 10$ \\
\hline $\begin{array}{l}\text { Guntupalli \& } \\
\text { Chenchelgudem } 2004\end{array}$ & $\mathrm{Y}$ & $\mathrm{Y}$ & $\mathrm{Y}$ & $\mathrm{Y}$ & $\mathrm{Y}$ & $\mathrm{N}$ & $\mathrm{Y}$ & $\mathrm{Y}$ & $\mathrm{Y}$ & $\mathrm{Y}$ & $9 / 10$ \\
\hline Lee et al. 2009 & Y & $\mathrm{Y}$ & Y & $\mathrm{Y}$ & Y & $\mathrm{Y}$ & Y & Y & Y & $\mathrm{Y}$ & $10 / 10$ \\
\hline McCarthy 2008 & Y & Y & Y & $\mathrm{Y}$ & Y & CT & $\mathrm{Y}$ & Y & $\mathrm{Y}$ & $\mathrm{Y}$ & $9 / 10$ \\
\hline Mogobe 2005 & Y & Y & Y & $\mathrm{Y}$ & $\mathrm{CT}$ & $\mathrm{N}$ & CT & Y & $\mathrm{Y}$ & $\mathrm{Y}$ & $7 / 10$ \\
\hline Mosalanejad et al. 2014 & Y & $\mathrm{Y}$ & Y & $\mathrm{Y}$ & Y & CT & $\mathrm{Y}$ & Y & $\mathrm{Y}$ & $\mathrm{Y}$ & $9 / 10$ \\
\hline Peddie et al. 2005 & Y & $\mathrm{Y}$ & Y & $\mathrm{Y}$ & Y & Y & $\mathrm{Y}$ & Y & $\mathrm{Y}$ & $\mathrm{Y}$ & $10 / 10$ \\
\hline Peters 2003 & Y & $\mathrm{Y}$ & Y & $\mathrm{Y}$ & Y & $\mathrm{N}$ & $\mathrm{Y}$ & Y & $\mathrm{Y}$ & $\mathrm{Y}$ & $9 / 10$ \\
\hline Peters et al. 2011 & Y & Y & Y & $\mathrm{Y}$ & Y & CT & $\mathrm{Y}$ & Y & $\mathrm{Y}$ & $\mathrm{Y}$ & $9 / 10$ \\
\hline Porter \& Bhattacharya 2008 & Y & $\mathrm{Y}$ & Y & $\mathrm{Y}$ & $\mathrm{Y}$ & Y & $\mathrm{Y}$ & Y & $\mathrm{Y}$ & $\mathrm{Y}$ & $10 / 10$ \\
\hline Roudsari \& Allan 2011 & Y & $\mathrm{Y}$ & Y & $\mathrm{Y}$ & $\mathrm{Y}$ & Y & Y & Y & $\mathrm{Y}$ & Y & $10 / 10$ \\
\hline Seybold 2012 & Y & $\mathrm{Y}$ & $\mathrm{Y}$ & $\mathrm{Y}$ & $\mathrm{Y}$ & Y & $\mathrm{N}$ & $\mathrm{N}$ & $\mathrm{Y}$ & $\mathrm{Y}$ & $8 / 10$ \\
\hline Silva et al. 2012 & Y & $\mathrm{Y}$ & Y & $\mathrm{U}$ & $\mathrm{Y}$ & $\mathrm{U}$ & $\mathrm{Y}$ & $\mathrm{Y}$ & $\mathrm{Y}$ & $\mathrm{Y}$ & $8 / 10$ \\
\hline Su \& Chen 2006 & Y & $\mathrm{Y}$ & Y & $\mathrm{Y}$ & $\mathrm{Y}$ & CT & Y & $\mathrm{Y}$ & $\mathrm{Y}$ & $\mathrm{Y}$ & $9 / 10$ \\
\hline $\begin{array}{l}\text { Toscano \& Montgomery } \\
2009\end{array}$ & $\mathrm{Y}$ & $\mathrm{Y}$ & $\mathrm{Y}$ & $\mathrm{Y}$ & $\mathrm{Y}$ & CT & $\mathrm{Y}$ & Y & $\mathrm{Y}$ & $\mathrm{Y}$ & $9 / 10$ \\
\hline
\end{tabular}

This article is protected by copyright. All rights reserved. 
Notes: $\mathrm{Y}-\mathrm{Yes}|\mathrm{N}-\mathrm{No}| \mathrm{CT}-\mathrm{Can}^{\prime} \mathrm{t}$ Tell

Q1 Was there a clear statement of the aims of the search?

Q2 Is a qualitative methodology appropriate?

Q3 Was the research design appropriate to address the aims of the research?

Q4 Was the recruitment strategy appropriate to the aims of the research?

Q5 Was the data collected in a way that addressed the research issue?
Q6 Has the relationship between researchers and participants been adequately considered?

Q7 Have ethical issues been taken into consideration?

Was the data analysis suffic iently rigorous?

Q9 Is there a clear statement of findings?

Q10 How valuable is the research?

This article is protected by copyright. All rights reserved. 
Table 3 - COREQ quality appraisal results.

\begin{tabular}{|c|c|c|c|c|c|c|c|c|c|c|c|c|c|c|c|c|c|c|c|c|c|c|c|c|c|c|c|c|c|c|c|}
\hline & & & 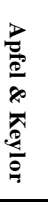 & 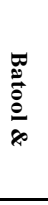 & 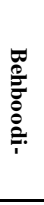 & 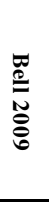 & 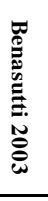 & 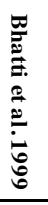 & 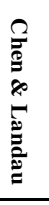 & 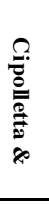 & 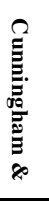 & 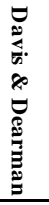 & 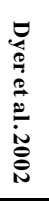 & 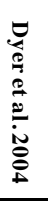 & $\underset{\infty}{\stackrel{\Omega}{E}}$ & 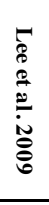 & 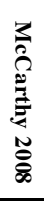 & 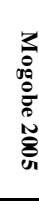 & 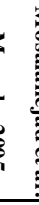 & 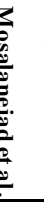 & 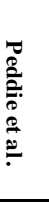 & 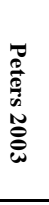 & 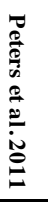 & 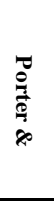 & 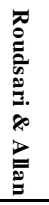 & 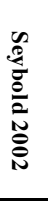 & 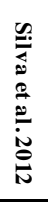 & 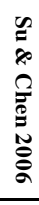 & & & \\
\hline \multirow{8}{*}{$\begin{array}{c}\text { DOM } \\
\text { AIN 1: } \\
\text { Resear } \\
\text { ch } \\
\text { team } \\
\text { and } \\
\text { reflexi } \\
\text { vity }\end{array}$} & \multirow{5}{*}{$\begin{array}{c}\text { Personal } \\
\text { Characteris } \\
\text { tics }\end{array}$} & $\begin{array}{l}\text { 1.Interviewer/facilit } \\
\text { ator }\end{array}$ & $\mathbf{N}$ & $\mathbf{U}$ & $\mathbf{Y}$ & $\mathbf{Y}$ & $\mathbf{Y}$ & $\mathbf{Y}$ & $\mathbf{Y}$ & $\mathbf{N}$ & $\mathbf{Y}$ & $\mathbf{N}$ & $\mathbf{N}$ & $\mathbf{N}$ & $\mathbf{N}$ & $\mathbf{Y}$ & $\mathbf{Y}$ & & $\mathbf{N}$ & $\mathbf{N}$ & $\mathbf{Y}$ & $\mathbf{Y}$ & $\mathbf{Y}$ & $\mathbf{Y}$ & $\mathbf{Y}$ & $\mathbf{Y}$ & $\mathbf{N}$ & $\mathbf{Y}$ & & $\mathbf{N}$ & 5 \\
\hline & & 2.Credentials & $\mathbf{N}$ & $\mathbf{U}$ & $\mathbf{U}$ & $\mathbf{Y}$ & $\mathbf{Y}$ & $\mathbf{Y}$ & $\mathbf{Y}$ & $\mathbf{N}$ & $\mathbf{Y}$ & $\mathbf{Y}$ & $\mathbf{N}$ & $\mathbf{N}$ & $\mathbf{N}$ & $\mathbf{N}$ & $\mathbf{Y}$ & & $\mathbf{N}$ & $\mathbf{Y}$ & $\mathbf{U}$ & $\mathbf{Y}$ & $\mathbf{N}$ & $\mathbf{N}$ & $\mathbf{Y}$ & $\mathbf{Y}$ & $\mathbf{Y}$ & $\mathbf{Y}$ & & $\mathbf{Y}$ & $\begin{array}{l}1 \\
4\end{array}$ \\
\hline & & 3.Occupation & $\mathbf{N}$ & $\mathbf{U}$ & $\mathbf{Y}$ & $\mathbf{N}$ & $\mathbf{U}$ & $\mathbf{Y}$ & $\mathbf{Y}$ & $\mathbf{N}$ & $\mathbf{Y}$ & $\mathbf{Y}$ & $\mathbf{Y}$ & $\mathbf{Y}$ & $\mathbf{Y}$ & $\mathbf{Y}$ & $\mathbf{Y}$ & & $\mathbf{N}$ & $\mathbf{Y}$ & $\mathbf{U}$ & $\mathbf{N}$ & $\mathbf{Y}$ & $\mathbf{N}$ & $\mathbf{Y}$ & $\mathbf{N}$ & $\mathbf{N}$ & $\mathbf{Y}$ & & $\mathbf{Y}$ & $\begin{array}{l}\mathbf{1} \\
\mathbf{5}\end{array}$ \\
\hline & & 4.Gender & $\mathbf{N}$ & $\mathbf{U}$ & $\mathbf{N}$ & $\mathbf{Y}$ & $\mathbf{Y}$ & $\mathbf{Y}$ & $\mathbf{N}$ & $\mathbf{N}$ & $\mathbf{N}$ & $\mathbf{Y}$ & $\mathbf{N}$ & $\mathbf{N}$ & $\mathbf{N}$ & $\mathbf{N}$ & $\mathbf{N}$ & & $\mathbf{N}$ & $\mathbf{N}$ & $\mathbf{U}$ & $\mathbf{Y}$ & $\mathbf{N}$ & $\mathbf{N}$ & $\mathbf{Y}$ & $\mathbf{Y}$ & $\mathbf{Y}$ & $\bar{N}$ & & $\mathbf{N}$ & 8 \\
\hline & & $\begin{array}{l}\text { 5.Experience and } \\
\text { training }\end{array}$ & $\mathbf{N}$ & $\mathbf{U}$ & $\mathbf{Y}$ & $\mathbf{N}$ & $\mathbf{Y}$ & $\mathbf{Y}$ & $\mathbf{N}$ & $\mathbf{N}$ & $\mathbf{N}$ & $\mathbf{Y}$ & $\mathbf{N}$ & $\mathbf{N}$ & $\mathbf{N}$ & $\mathbf{N}$ & $\mathbf{Y}$ & & $\mathbf{N}$ & $\mathbf{N}$ & $\mathbf{U}$ & $\mathbf{N}$ & $\mathbf{N}$ & $\mathbf{N}$ & $\mathbf{Y}$ & $\mathbf{N}$ & $\mathbf{N}$ & $N$ & & $\mathbf{N}$ & 6 \\
\hline & \multirow{3}{*}{$\begin{array}{c}\text { Relationshi } \\
\text { p with } \\
\text { participants }\end{array}$} & $\begin{array}{l}\text { 6.Relashionship } \\
\text { established } \\
\end{array}$ & $\mathbf{Y}$ & $\mathbf{Y}$ & $\mathbf{Y}$ & $\mathbf{N}$ & $\mathbf{Y}$ & $\mathbf{Y}$ & $\mathbf{N}$ & $\mathbf{Y}$ & $\mathbf{Y}$ & $\mathbf{N}$ & $\mathbf{N}$ & $\mathbf{N}$ & $\mathbf{N}$ & $\mathbf{Y}$ & $\mathbf{N}$ & & $\mathbf{N}$ & $\mathbf{N}$ & $\mathbf{Y}$ & $\mathbf{N}$ & $\mathbf{Y}$ & $\mathbf{Y}$ & $\mathbf{Y}$ & $\mathbf{Y}$ & $\mathbf{U}$ & $\mathbf{Y}$ & & $\mathbf{N}$ & $\begin{array}{l}1 \\
4 \\
\end{array}$ \\
\hline & & $\begin{array}{l}\text { 7.P articipants } \\
\text { knowledge of the } \\
\text { interviewer }\end{array}$ & $\mathbf{Y}$ & $\mathbf{Y}$ & $\mathbf{N}$ & $\mathbf{N}$ & $\mathbf{Y}$ & $\mathbf{U}$ & $\mathbf{N}$ & $\mathbf{Y}$ & $\mathbf{N}$ & $\mathbf{U}$ & $\mathbf{N}$ & $\mathbf{N}$ & $\mathbf{N}$ & $\mathbf{U}$ & $\mathbf{N}$ & & $\mathbf{N}$ & $\mathbf{N}$ & $\mathbf{Y}$ & $\mathbf{N}$ & $\mathbf{N}$ & $\mathbf{U}$ & $\mathbf{U}$ & $\mathbf{U}$ & $\mathbf{N}$ & $N$ & & $\mathbf{N}$ & 5 \\
\hline & & $\begin{array}{l}\text { 8.Interviewer } \\
\text { characteristics }\end{array}$ & $\mathbf{Y}$ & $\mathbf{Y}$ & $\mathbf{N}$ & $\mathbf{U}$ & $\mathbf{Y}$ & $\mathbf{Y}$ & $\mathbf{N}$ & $\mathbf{N}$ & $\mathbf{N}$ & $\mathbf{N}$ & $\mathbf{N}$ & $\mathbf{N}$ & $\mathbf{N}$ & $\mathbf{Y}$ & $\mathbf{N}$ & & $\mathbf{N}$ & $\mathbf{N}$ & $\mathbf{N}$ & $\mathbf{N}$ & $\mathbf{N}$ & $\mathbf{Y}$ & $\mathbf{U}$ & $\mathbf{U}$ & $\mathbf{N}$ & N & & $\mathbf{N}$ & 6 \\
\hline \multirow{15}{*}{\begin{tabular}{c|} 
\\
\\
DOM \\
AIN 2: \\
Study \\
design
\end{tabular}} & $\begin{array}{l}\text { Theoretical } \\
\text { framework }\end{array}$ & $\begin{array}{l}\text { 9.Methodological } \\
\text { orientation and } \\
\text { Theory }\end{array}$ & $\mathbf{Y}$ & $\mathbf{Y}$ & $\mathbf{Y}$ & $\mathbf{Y}$ & $\mathbf{Y}$ & $\mathbf{Y}$ & $\mathbf{Y}$ & $\mathbf{Y}$ & $\mathbf{Y}$ & $\mathbf{Y}$ & $\mathbf{Y}$ & $\mathbf{Y}$ & $\mathbf{N}$ & $\mathbf{Y}$ & $\mathbf{Y}$ & & $\mathbf{Y}$ & $\mathbf{Y}$ & $\mathbf{Y}$ & $\mathbf{Y}$ & $\mathbf{Y}$ & $\mathbf{Y}$ & $\mathbf{Y}$ & $\mathbf{Y}$ & $\mathbf{Y}$ & $Y$ & & $\mathbf{Y}$ & $\begin{array}{l}2 \\
5\end{array}$ \\
\hline & \multirow{4}{*}{$\begin{array}{l}\text { Participant } \\
\text { selection }\end{array}$} & 10.Sampling & $\mathbf{N}$ & $\mathbf{Y}$ & $\mathbf{Y}$ & $\mathbf{Y}$ & $\mathbf{Y}$ & $\mathbf{Y}$ & $\mathbf{Y}$ & $\mathbf{Y}$ & $\mathbf{Y}$ & $\mathbf{Y}$ & $\mathbf{Y}$ & $\mathbf{Y}$ & $\mathbf{Y}$ & $\mathbf{Y}$ & $\mathbf{Y}$ & & $\mathbf{Y}$ & $\mathbf{Y}$ & $\mathbf{Y}$ & $\mathbf{Y}$ & $\mathbf{Y}$ & $\mathbf{Y}$ & $\mathbf{Y}$ & $\mathbf{Y}$ & $\mathbf{N}$ & $\mathbf{Y}$ & & $\mathbf{Y}$ & $\begin{array}{l}2 \\
4 \\
\end{array}$ \\
\hline & & $\begin{array}{l}\text { 11.Method of } \\
\text { approach }\end{array}$ & $\mathbf{N}$ & $\mathbf{Y}$ & $\mathbf{Y}$ & $\mathbf{Y}$ & $\mathbf{Y}$ & $\mathbf{Y}$ & $\mathbf{Y}$ & $\mathbf{Y}$ & $\mathbf{Y}$ & $\mathbf{Y}$ & $\mathbf{Y}$ & $\mathbf{Y}$ & $\mathbf{N}$ & $\mathbf{Y}$ & $\mathbf{Y}$ & & $\mathbf{Y}$ & $\mathbf{Y}$ & $\mathbf{Y}$ & $\mathbf{Y}$ & $\mathbf{Y}$ & $\mathbf{Y}$ & $\mathbf{Y}$ & $\mathbf{Y}$ & $\mathbf{Y}$ & $\mathbf{Y}$ & & $\mathbf{Y}$ & $\begin{array}{l}2 \\
5\end{array}$ \\
\hline & & 12.Sample size & $\mathbf{Y}$ & $\mathbf{Y}$ & $\mathbf{Y}$ & $\mathbf{Y}$ & $\mathbf{Y}$ & $\mathbf{Y}$ & $\mathbf{Y}$ & $\mathbf{Y}$ & $\mathbf{Y}$ & $\mathbf{Y}$ & $\mathbf{Y}$ & $\mathbf{Y}$ & $\mathbf{Y}$ & $\mathbf{Y}$ & $\mathbf{Y}$ & & $\mathbf{Y}$ & $\mathbf{Y}$ & $\mathbf{Y}$ & $\mathbf{Y}$ & $\mathbf{Y}$ & $\mathbf{Y}$ & $\mathbf{Y}$ & $\mathbf{Y}$ & $\mathbf{Y}$ & $\mathbf{Y}$ & & $\mathbf{Y}$ & $\begin{array}{l}2 \\
6 \\
\end{array}$ \\
\hline & & 13.Non-participation & $\mathbf{N}$ & $\mathbf{N}$ & $\mathbf{N}$ & $\mathbf{N}$ & $\mathbf{N}$ & $\mathbf{Y}$ & $\mathbf{Y}$ & $\mathbf{Y}$ & $\mathbf{Y}$ & $\mathbf{N}$ & $\mathbf{Y}$ & $\mathbf{Y}$ & $\mathbf{N}$ & $\mathbf{Y}$ & $\mathbf{N}$ & & $\mathbf{N}$ & $\mathbf{N}$ & $\mathbf{Y}$ & $\mathbf{N}$ & $\mathbf{Y}$ & $\mathbf{Y}$ & $\mathbf{Y}$ & $\mathbf{N}$ & $\mathbf{N}$ & 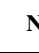 & & $\mathbf{N}$ & $\begin{array}{l}1 \\
1\end{array}$ \\
\hline & \multirow{3}{*}{ Setting } & $\begin{array}{l}14 . \text { Set } \\
\text { collec }\end{array}$ & $\mathbf{Y}$ & $\mathbf{U}$ & $\mathbf{Y}$ & $\mathbf{Y}$ & $\mathbf{Y}$ & $\mathbf{Y}$ & $\mathbf{Y}$ & $\mathbf{Y}$ & $\mathbf{Y}$ & $\mathbf{U}$ & $\mathbf{Y}$ & $\mathbf{Y}$ & $\mathbf{Y}$ & $\mathbf{Y}$ & $\mathbf{Y}$ & & $\mathbf{Y}$ & $\mathbf{Y}$ & $\mathbf{Y}$ & $\mathbf{U}$ & $\mathbf{Y}$ & $\mathbf{Y}$ & $\mathbf{Y}$ & $\mathbf{Y}$ & $\mathbf{U}$ & $\mathbf{Y}$ & & $\mathbf{Y}$ & $\begin{array}{l}2 \\
2 \\
\end{array}$ \\
\hline & & $\begin{array}{l}\text { se ofnon- } \\
\text { s }\end{array}$ & $\mathbf{N}$ & $\mathbf{N}$ & $\mathbf{Y}$ & $\mathbf{N}$ & $\mathbf{N}$ & $\mathbf{Y}$ & $\mathbf{N}$ & $\mathbf{Y}$ & $\mathbf{N}$ & $\mathbf{N}$ & $\mathbf{Y}$ & $\mathbf{Y}$ & $\mathbf{N}$ & $\mathbf{Y}$ & $\mathbf{N}$ & & $\mathbf{N}$ & $\mathbf{N}$ & $\mathbf{N}$ & $\mathbf{N}$ & $\mathbf{N}$ & $\mathbf{N}$ & $\mathbf{N}$ & $\mathbf{N}$ & $\mathbf{N}$ & $\mathbf{N}$ & & $\mathbf{N}$ & 6 \\
\hline & & $\begin{array}{l}\text { 16.Description of } \\
\text { sample }\end{array}$ & $\mathbf{Y}$ & $\mathbf{Y}$ & $\mathbf{Y}$ & $\mathbf{Y}$ & $\mathbf{Y}$ & $\mathbf{Y}$ & $\mathbf{Y}$ & $\mathbf{Y}$ & $\mathbf{Y}$ & $\mathbf{Y}$ & $\mathbf{Y}$ & $\mathbf{Y}$ & $\mathbf{Y}$ & $\mathbf{Y}$ & $\mathbf{Y}$ & & $\mathbf{Y}$ & $\mathbf{Y}$ & $\mathbf{Y}$ & $\mathbf{Y}$ & $\mathbf{Y}$ & $\mathbf{Y}$ & $\mathbf{Y}$ & $\mathbf{Y}$ & $\mathbf{Y}$ & $\mathbf{Y}$ & & $\mathbf{N}$ & $\begin{array}{l}2 \\
5 \\
\end{array}$ \\
\hline & \multirow{7}{*}{$\begin{array}{c}\text { Data } \\
\text { collection }\end{array}$} & 17.Interview guide & $\mathbf{N}$ & $\mathbf{N}$ & $\mathbf{Y}$ & $\mathbf{Y}$ & $\mathbf{Y}$ & $\mathbf{Y}$ & $\mathbf{Y}$ & $\mathbf{Y}$ & $\mathbf{Y}$ & $\mathbf{Y}$ & $\mathbf{Y}$ & $\mathbf{Y}$ & $\mathbf{Y}$ & $\mathbf{Y}$ & $\mathbf{Y}$ & & $\mathbf{Y}$ & $\mathbf{Y}$ & $\mathbf{U}$ & $\mathbf{Y}$ & $\mathbf{Y}$ & $\mathbf{Y}$ & $\mathbf{Y}$ & $\mathbf{N}$ & $\mathbf{Y}$ & $\mathbf{Y}$ & & $\mathbf{Y}$ & $\begin{array}{l}2 \\
2 \\
\end{array}$ \\
\hline & & $\begin{array}{l}\text { 18.Repeat } \\
\text { interviews } \\
\end{array}$ & $\mathbf{Y}$ & $\mathbf{N}$ & $\mathbf{N}$ & $\mathbf{N}$ & $\mathbf{Y}$ & $\mathbf{N}$ & $\mathbf{N}$ & $\mathbf{N}$ & $\mathbf{N}$ & $\mathbf{N}$ & $\mathbf{N}$ & $\mathbf{N}$ & $\mathbf{N}$ & $\mathbf{Y}$ & $\mathbf{N}$ & & $\mathbf{N}$ & $\mathbf{N}$ & $\mathbf{N}$ & $\mathbf{N}$ & $\mathbf{N}$ & $\mathbf{Y}$ & $\mathbf{Y}$ & $\mathbf{N}$ & $\mathbf{N}$ & $\mathbf{N}$ & & $\mathbf{N}$ & $\begin{array}{l}2 \\
1 \\
\end{array}$ \\
\hline & & $\begin{array}{l}19 . \text { Audio/visual } \\
\text { recording }\end{array}$ & $\mathbf{N}$ & $\mathbf{N}$ & $\mathbf{Y}$ & $\mathbf{N}$ & $\mathbf{Y}$ & $\mathbf{Y}$ & $\mathbf{Y}$ & $\mathbf{Y}$ & $\mathbf{N}$ & $\mathbf{Y}$ & $\mathbf{Y}$ & $\mathbf{Y}$ & $\mathbf{N}$ & $\mathbf{Y}$ & $\mathbf{Y}$ & & $\mathbf{N}$ & $\mathbf{Y}$ & $\mathbf{Y}$ & $\mathbf{Y}$ & $\mathbf{Y}$ & $\mathbf{Y}$ & $\mathbf{Y}$ & $\mathbf{N}$ & $\mathbf{Y}$ & $\mathbf{Y}$ & & $\mathbf{N}$ & $\begin{array}{l}1 \\
8 \\
\end{array}$ \\
\hline & & 20.Field notes & $\mathbf{N}$ & $\mathbf{N}$ & $\mathbf{N}$ & $\mathbf{N}$ & $\mathbf{Y}$ & $\mathbf{Y}$ & $\mathbf{N}$ & $\mathbf{N}$ & $\mathbf{N}$ & $\mathbf{N}$ & $\mathbf{N}$ & $\mathbf{Y}$ & $\mathbf{N}$ & $\mathbf{Y}$ & $\mathbf{N}$ & & $\mathbf{N}$ & $\mathbf{Y}$ & $\mathbf{N}$ & $\mathbf{N}$ & $\mathbf{N}$ & $\mathbf{N}$ & $\mathbf{Y}$ & $\mathbf{Y}$ & $\mathbf{N}$ & $\underline{N}$ & & $\mathbf{N}$ & 7 \\
\hline & & 21.Duration & $\mathbf{N}$ & $\mathbf{Y}$ & $\mathbf{Y}$ & $\mathbf{Y}$ & $\mathbf{Y}$ & $\mathbf{Y}$ & $\mathbf{Y}$ & $\mathbf{Y}$ & $\mathbf{Y}$ & $\mathbf{Y}$ & $\mathbf{N}$ & $\mathbf{U}$ & $\mathbf{N}$ & $\mathbf{Y}$ & $\mathbf{Y}$ & & $\mathbf{Y}$ & $\mathbf{Y}$ & $\mathbf{Y}$ & $\mathbf{Y}$ & $\mathbf{Y}$ & $\mathbf{Y}$ & $\mathbf{Y}$ & $\mathbf{Y}$ & $\mathbf{N}$ & $\mathbf{Y}$ & & $\mathbf{Y}$ & $\begin{array}{l}2 \\
1\end{array}$ \\
\hline & & 22.Data saturation & $\mathbf{N}$ & $\mathbf{N}$ & $\mathbf{N}$ & $\mathbf{N}$ & $\mathbf{N}$ & $\mathbf{Y}$ & $\mathbf{Y}$ & $\mathbf{Y}$ & $\mathbf{Y}$ & $\mathbf{N}$ & $\mathbf{N}$ & $\mathbf{Y}$ & $\mathbf{N}$ & $\mathbf{Y}$ & $\mathbf{Y}$ & & $\mathbf{N}$ & $\mathbf{N}$ & $\mathbf{N}$ & $\mathbf{N}$ & $\mathbf{N}$ & $\mathbf{Y}$ & $\mathbf{Y}$ & $\mathbf{N}$ & $\mathbf{N}$ & $\mathbf{N}$ & N & $\mathbf{Y}$ & $\begin{array}{l}1 \\
0\end{array}$ \\
\hline & & $\begin{array}{l}23 . \mathrm{T} \\
\text { retur }\end{array}$ & $\mathbf{N}$ & $\mathbf{N}$ & $\mathbf{N}$ & $\mathbf{N}$ & $\mathbf{N}$ & $\mathbf{Y}$ & $\mathbf{N}$ & $\mathbf{N}$ & $\mathbf{N}$ & $\mathbf{N}$ & $\mathbf{N}$ & $\mathbf{N}$ & $\mathbf{N}$ & $\mathbf{Y}$ & $\mathbf{N}$ & & $\mathbf{N}$ & $\mathbf{U}$ & $\mathbf{N}$ & $\mathbf{N}$ & $\mathbf{N}$ & $\mathbf{Y}$ & $\mathbf{N}$ & $\mathbf{N}$ & $\mathbf{N}$ & $\mathbf{N}$ & & $\mathbf{N}$ & $\begin{array}{l}2 \\
3\end{array}$ \\
\hline \multirow{9}{*}{$\begin{array}{l}\text { DOM } \\
\text { AIN 3: } \\
\text { Analys } \\
\text { is and } \\
\text { findin } \\
\text { gs }\end{array}$} & \multirow{5}{*}{$\begin{array}{c}\text { Data } \\
\text { analysis }\end{array}$} & $\begin{array}{l}\text { 24.Number of data } \\
\text { coders }\end{array}$ & $\mathbf{N}$ & $\mathbf{Y}$ & $\mathbf{Y}$ & $\mathbf{N}$ & $\mathbf{Y}$ & $\mathbf{Y}$ & $\mathbf{N}$ & $\mathbf{Y}$ & $\mathbf{Y}$ & $\mathbf{Y}$ & $\mathbf{N}$ & $\mathbf{Y}$ & $\mathbf{N}$ & $\mathbf{Y}$ & $\mathbf{Y}$ & & $\mathbf{U}$ & $\mathbf{Y}$ & $\mathbf{Y}$ & $\mathbf{Y}$ & $\mathbf{N}$ & $\mathbf{Y}$ & $\mathbf{Y}$ & $\mathbf{Y}$ & $\mathbf{N}$ & $\mathbf{Y}$ & & $\mathbf{N}$ & $\begin{array}{l}1 \\
7 \\
\end{array}$ \\
\hline & & $\begin{array}{l}\text { 25.Description of } \\
\text { the coding tree }\end{array}$ & $\mathbf{N}$ & $\mathbf{N}$ & $\mathbf{N}$ & $\mathbf{N}$ & $\mathbf{N}$ & $\mathbf{Y}$ & $\mathbf{N}$ & $\mathbf{N}$ & $\mathbf{N}$ & $\mathbf{N}$ & $\mathbf{N}$ & $\mathbf{N}$ & $\mathbf{N}$ & $\mathbf{Y}$ & $\mathbf{N}$ & & $\mathbf{N}$ & $\mathbf{U}$ & $\mathbf{N}$ & $\mathbf{N}$ & $\mathbf{N}$ & $\mathbf{N}$ & $\mathbf{N}$ & $\mathbf{N}$ & $\mathbf{N}$ & $\mathbf{Y}$ & & $\mathbf{N}$ & 3 \\
\hline & & $\begin{array}{l}\text { 26.Derivation of } \\
\text { themes }\end{array}$ & $\mathbf{N}$ & $\mathbf{Y}$ & $\mathbf{Y}$ & $\mathbf{Y}$ & $\mathbf{Y}$ & $\mathbf{Y}$ & $\mathbf{Y}$ & $\mathbf{Y}$ & $\mathbf{Y}$ & $\mathbf{Y}$ & $\mathbf{Y}$ & $\mathbf{Y}$ & $\mathbf{N}$ & $\mathbf{Y}$ & $\mathbf{Y}$ & & $\mathbf{N}$ & $\mathbf{Y}$ & $\mathbf{Y}$ & $\mathbf{Y}$ & $\mathbf{Y}$ & $\mathbf{Y}$ & $\mathbf{Y}$ & $\mathbf{Y}$ & $\mathbf{Y}$ & $\mathbf{Y}$ & & $\mathbf{Y}$ & $\begin{array}{l}2 \\
3 \\
\end{array}$ \\
\hline & & 27.Software & $\mathbf{N}$ & $\mathbf{N}$ & $\mathbf{N}$ & $\mathbf{Y}$ & $\mathbf{Y}$ & $\mathbf{N}$ & $\mathbf{N}$ & $\mathbf{N}$ & $\mathbf{Y}$ & $\mathbf{N}$ & $\mathbf{N}$ & $\mathbf{N}$ & $\mathbf{N}$ & $\mathbf{N}$ & $\mathbf{N}$ & & $\mathbf{N}$ & $\mathbf{N}$ & $\mathbf{N}$ & $\mathbf{N}$ & $\mathbf{N}$ & $\mathbf{N}$ & $\mathbf{N}$ & $\mathbf{N}$ & $\mathbf{N}$ & $N$ & & $\mathbf{Y}$ & $\begin{array}{l}2 \\
2\end{array}$ \\
\hline & & $\begin{array}{l}\text { 28.Participant } \\
\text { checking }\end{array}$ & $\mathbf{N}$ & $\mathbf{N}$ & $\mathbf{Y}$ & $\mathbf{N}$ & $\mathbf{Y}$ & $\mathbf{Y}$ & $\mathbf{N}$ & $\mathbf{N}$ & $\mathbf{Y}$ & $\mathbf{N}$ & $\mathbf{N}$ & $\mathbf{N}$ & $\mathbf{N}$ & $\mathbf{Y}$ & $\mathbf{N}$ & & $\mathbf{N}$ & $\mathbf{N}$ & $\mathbf{N}$ & $\mathbf{N}$ & $\mathbf{N}$ & $\mathbf{Y}$ & $\mathbf{Y}$ & $\mathbf{N}$ & $\mathbf{N}$ & $\mathbf{Y}$ & & $\mathbf{N}$ & 8 \\
\hline & \multirow{4}{*}{ Reporting } & $\begin{array}{l}\text { 29.Quotations } \\
\text { presented }\end{array}$ & $\mathbf{N}$ & $\mathbf{Y}$ & $\mathbf{Y}$ & $\mathbf{Y}$ & $\mathbf{Y}$ & $\mathbf{Y}$ & $\mathbf{Y}$ & $\mathbf{Y}$ & $\mathbf{Y}$ & $\mathbf{Y}$ & $\mathbf{Y}$ & $\mathbf{Y}$ & $\mathbf{Y}$ & $\mathbf{Y}$ & $\mathbf{Y}$ & & $\mathbf{Y}$ & $\mathbf{Y}$ & $\mathbf{Y}$ & $\mathbf{Y}$ & $\mathbf{Y}$ & $\mathbf{Y}$ & $\mathbf{Y}$ & $\mathbf{Y}$ & $\mathbf{Y}$ & $\mathbf{Y}$ & 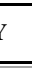 & $\mathbf{Y}$ & $\begin{array}{l}2 \\
5 \\
\end{array}$ \\
\hline & & $\begin{array}{l}\text { 30.Data and findings } \\
\text { consistent }\end{array}$ & $\mathbf{N}$ & $\mathbf{Y}$ & $\mathbf{Y}$ & $\mathbf{Y}$ & $\mathbf{Y}$ & $\mathbf{Y}$ & $\mathbf{Y}$ & $\mathbf{Y}$ & $\mathbf{Y}$ & $\mathbf{Y}$ & $\mathbf{Y}$ & $\mathbf{Y}$ & $\mathbf{Y}$ & $\mathbf{Y}$ & $\mathbf{Y}$ & & $\mathbf{Y}$ & $\mathbf{Y}$ & $\mathbf{Y}$ & $\mathbf{Y}$ & $\mathbf{Y}$ & $\mathbf{Y}$ & $\mathbf{Y}$ & $\mathbf{Y}$ & $\mathbf{Y}$ & $\mathbf{Y}$ & $Y$ & $\mathbf{Y}$ & $\begin{array}{l}2 \\
5 \\
\end{array}$ \\
\hline & & $\begin{array}{l}\text { 31.Clarity of major } \\
\text { themes }\end{array}$ & $\mathbf{N}$ & $\mathbf{Y}$ & $\mathbf{Y}$ & $\mathbf{Y}$ & $\mathbf{Y}$ & $\mathbf{Y}$ & $\mathbf{Y}$ & $\mathbf{Y}$ & $\mathbf{Y}$ & $\mathbf{Y}$ & $\mathbf{Y}$ & $\mathbf{Y}$ & $\mathbf{Y}$ & $\mathbf{Y}$ & $\mathbf{Y}$ & & $\mathbf{Y}$ & $\mathbf{Y}$ & $\mathbf{Y}$ & $\mathbf{Y}$ & $\mathbf{Y}$ & $\mathbf{Y}$ & $\mathbf{Y}$ & $\mathbf{Y}$ & $\mathbf{Y}$ & $\mathbf{Y}$ & & Y & $\begin{array}{l}2 \\
5 \\
\end{array}$ \\
\hline & & $\begin{array}{l}\text { 32.Clarity of minor } \\
\text { themes }\end{array}$ & $\mathbf{N}$ & $\mathbf{Y}$ & $\mathbf{Y}$ & $\mathbf{N}$ & $\mathbf{Y}$ & $\mathbf{Y}$ & $\mathbf{Y}$ & $\mathbf{Y}$ & $\mathbf{Y}$ & $\mathbf{N}$ & $\mathbf{Y}$ & $\mathbf{Y}$ & $\mathbf{Y}$ & $\mathbf{Y}$ & $\mathbf{Y}$ & & $\mathbf{Y}$ & $\mathbf{Y}$ & $\mathbf{N}$ & $\mathbf{Y}$ & $\mathbf{Y}$ & $\mathbf{Y}$ & $\mathbf{Y}$ & $\mathbf{Y}$ & $\mathbf{N}$ & $\mathbf{Y}$ & $Y$ & $\mathbf{Y}$ & $\begin{array}{l}2 \\
1 \\
\end{array}$ \\
\hline & \multirow{2}{*}{ RESULTS } & \multirow{2}{*}{$\mathbf{Y}$ - Yes } & 8 & 1 & 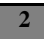 & 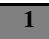 & 2 & 2 & $\overline{1}$ & 2 & 2 & 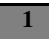 & $\overline{1}$ & 1 & 1 & 2 & 5 & & $\overline{1}$ & 1 & 1 & 1 & 1 & 2 & 2 & 1 & 1 & 2 & & 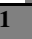 & \\
\hline & & & & 5 & 1 & 6 & 6 & 9 & 9 & $\mathbf{0}$ & 2 & 7 & 6 & 3 & 0 & 1 & 0 & & 2 & 0 & 7 & 7 & 8 & 4 & $\mathbf{0}$ & 0 & 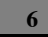 & 1 & & & \\
\hline & & \multirow{2}{*}{$\mathbf{N}$ - No } & 2 & 1 & 1 & 1 & 5 & 1 & 1 & 1 & 1 & 1 & 1 & 1 & 2 & 4 & 1 & & 1 & 1 & 1 & 1 & 1 & 7 & 4 & 1 & 1 & $\overline{1}$ & & 1 & \\
\hline & & & 4 & 1 & 0 & 5 & & & 3 & 2 & 0 & 3 & 6 & 2 & 2 & & 2 & & $\underline{9}$ & 2 & 0 & 4 & 4 & & & 2 & 4 & 1 & & 6 & \\
\hline & & U - Unclear & 0 & 6 & 1 & 1 & 1 & 2 & 0 & 0 & 0 & 2 & 0 & 1 & $\mathbf{0}$ & 1 & 0 & & 1 & 2 & 5 & 1 & 0 & 1 & 2 & 2 & 2 & 0 & & $\overline{0}$ & \\
\hline
\end{tabular}

Notes: Y- Yes $\mid \mathrm{N}$ - No|U-Unclear

This article is protected by copyright. All rights reserved. 


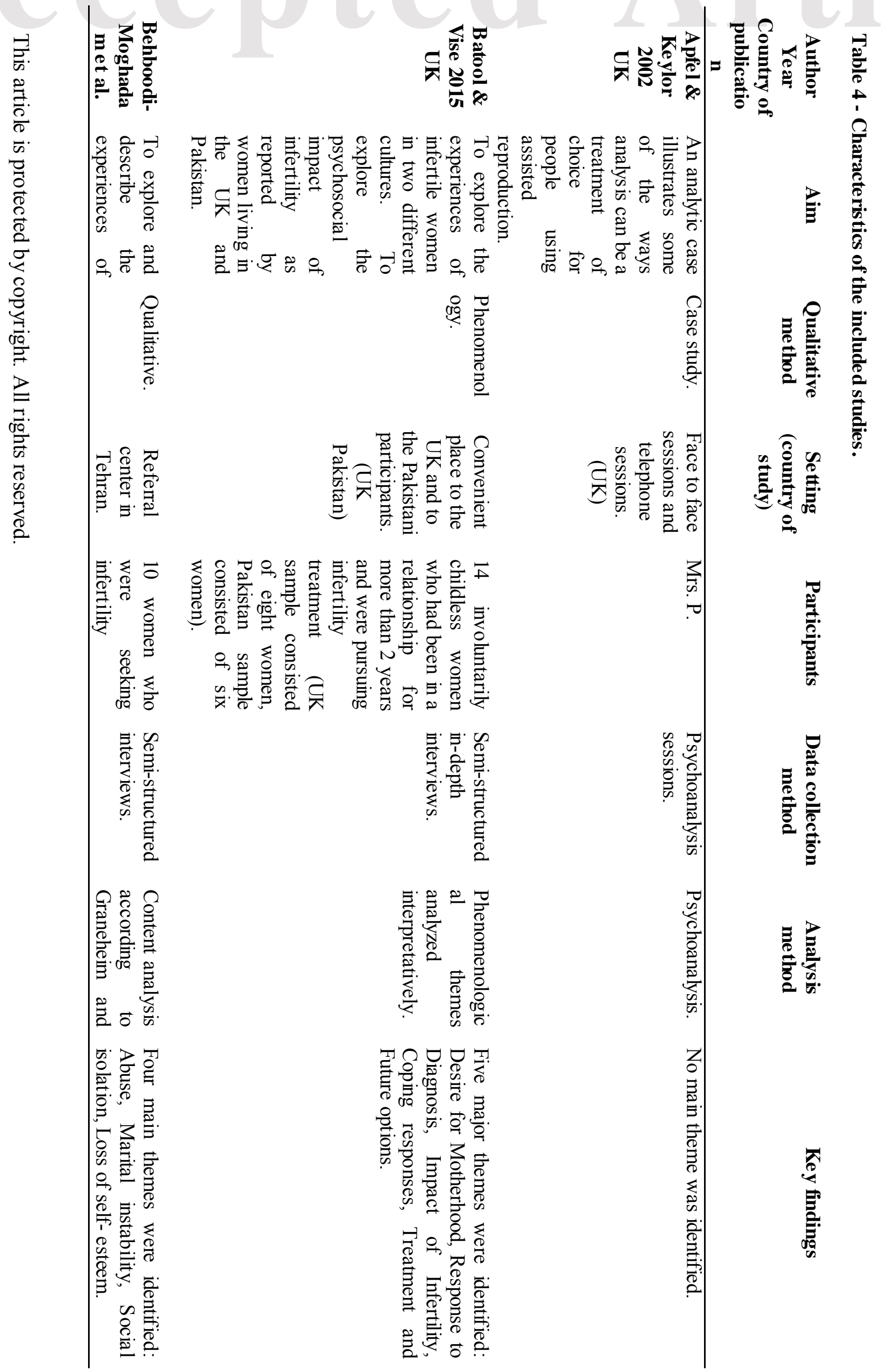




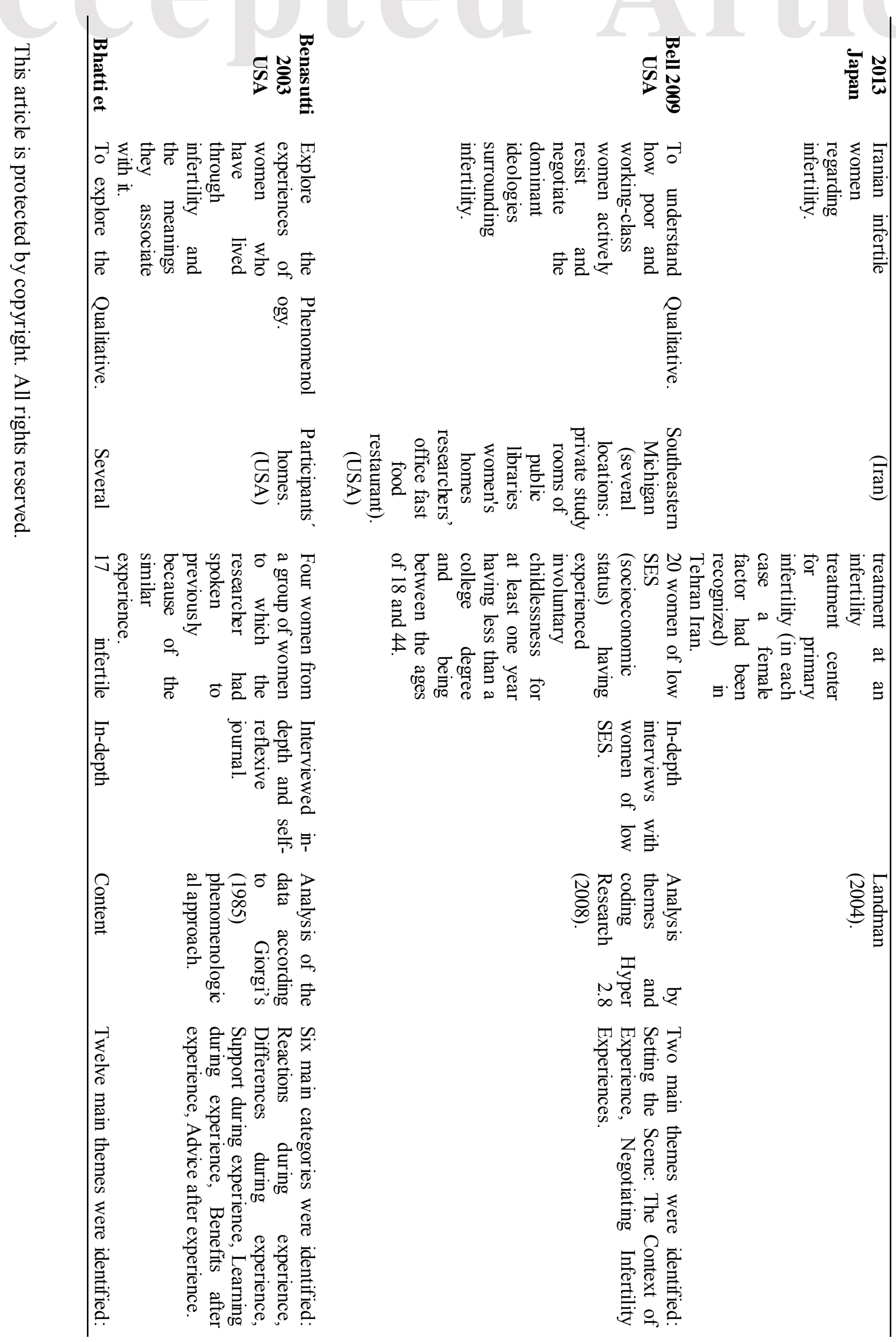




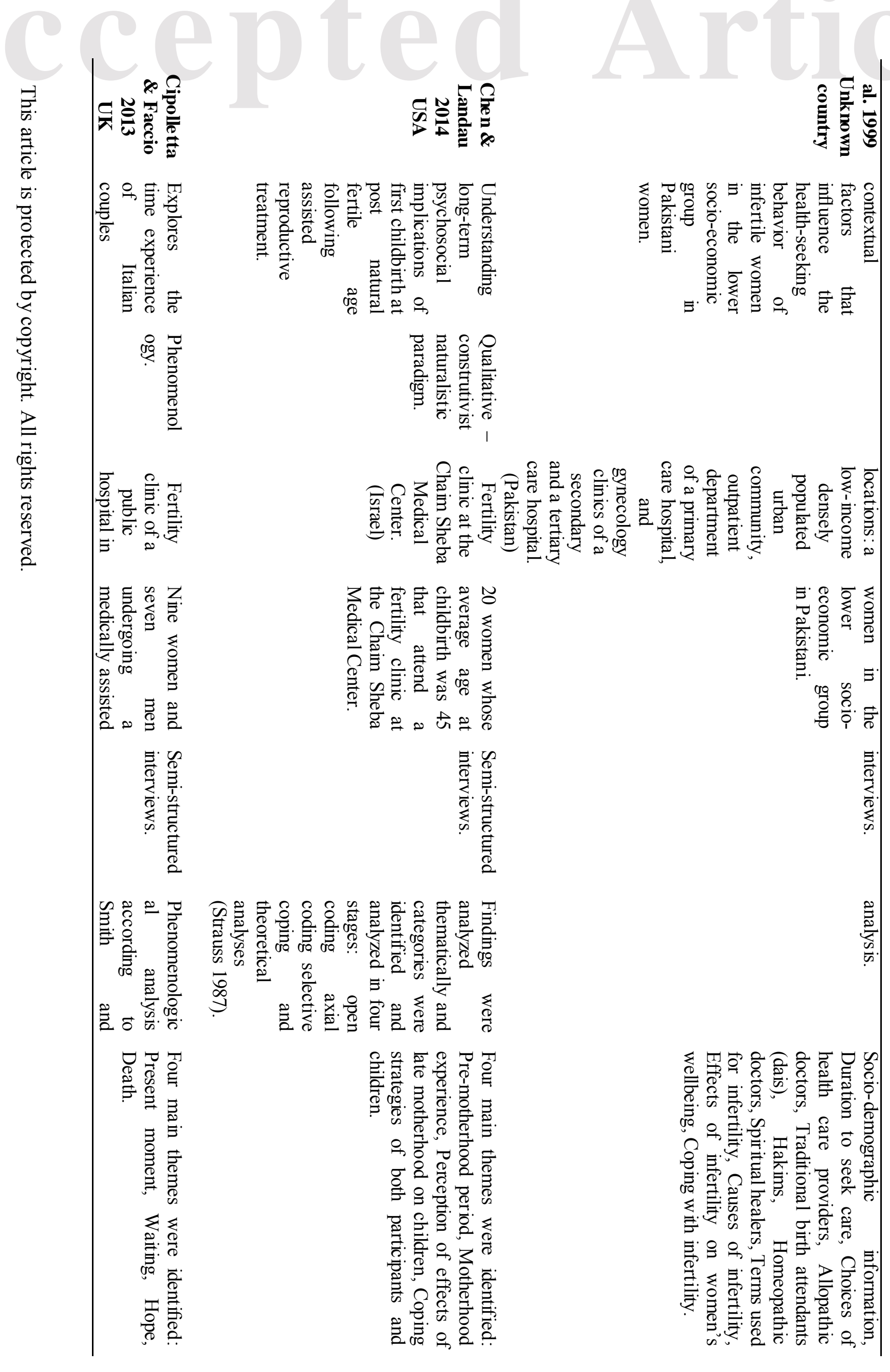




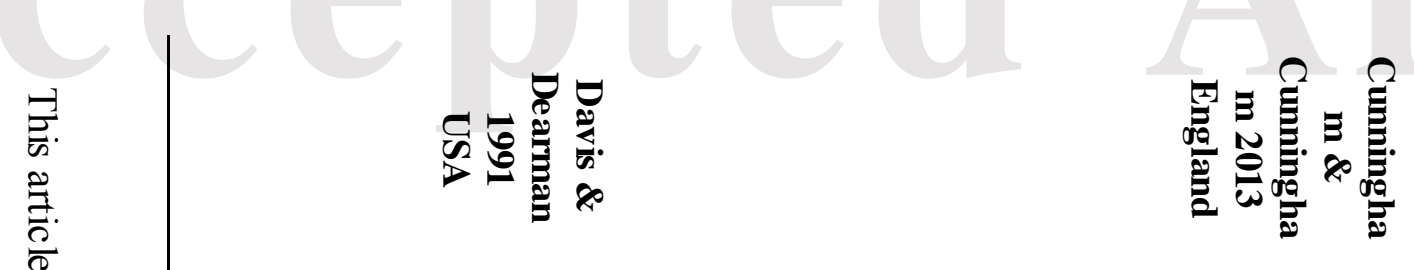

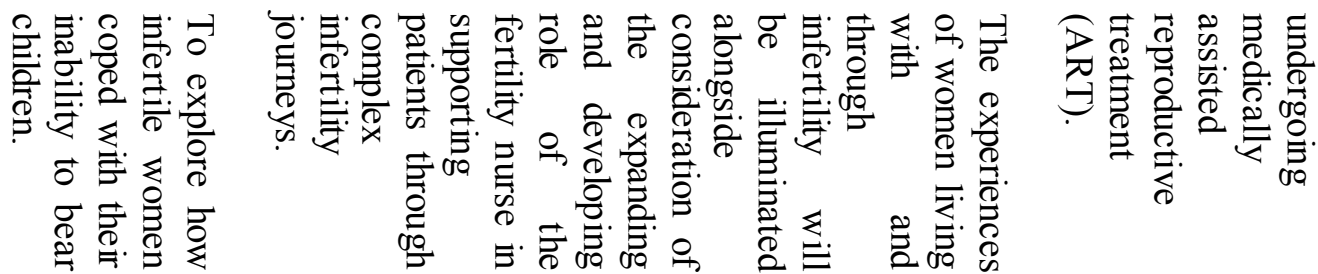

.

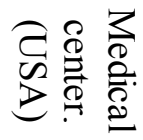

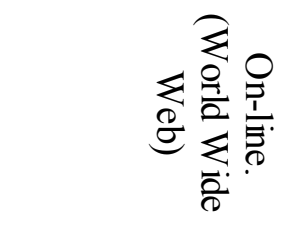

@

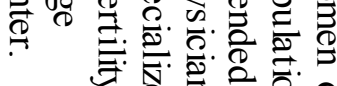
₹

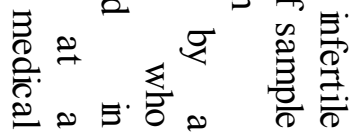

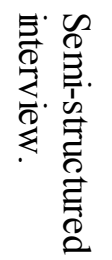

$$
\text { 苛. }
$$

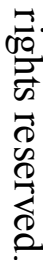
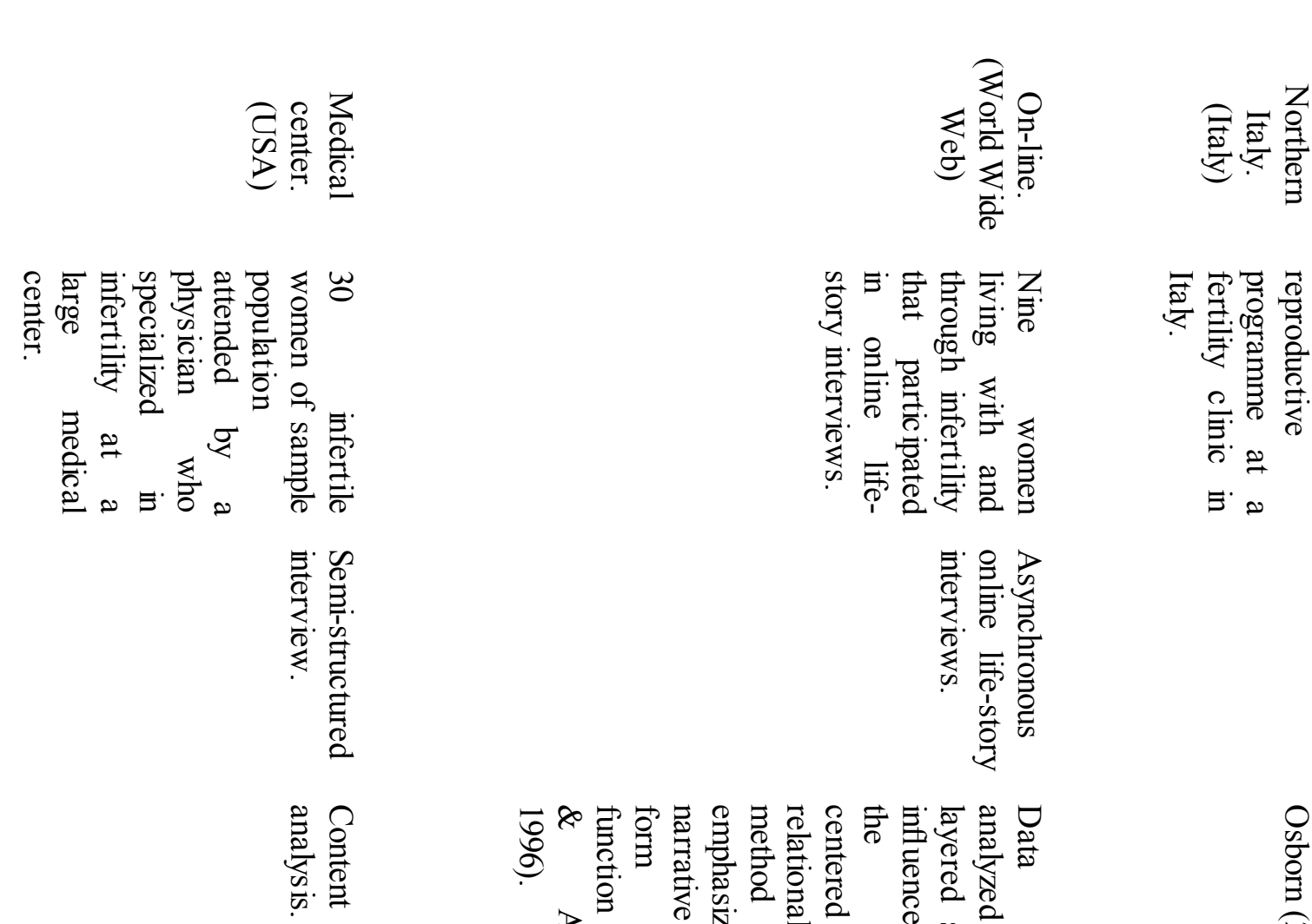

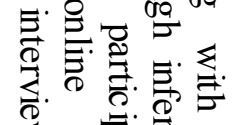

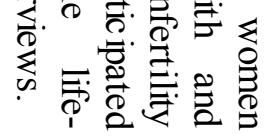

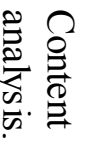
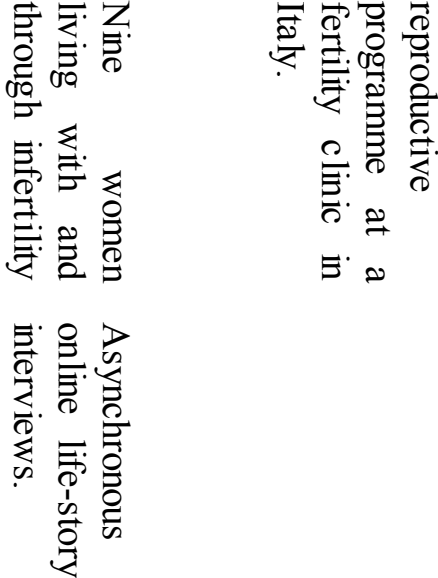

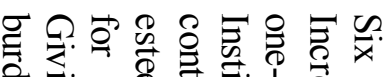
实志

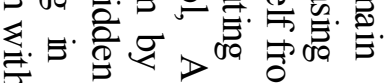

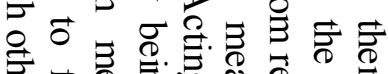
बे के क्ष 音.

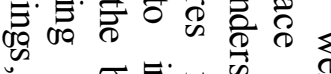
水审

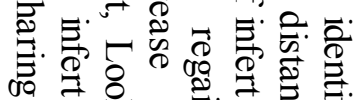

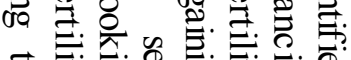

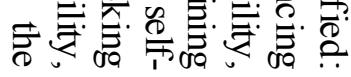
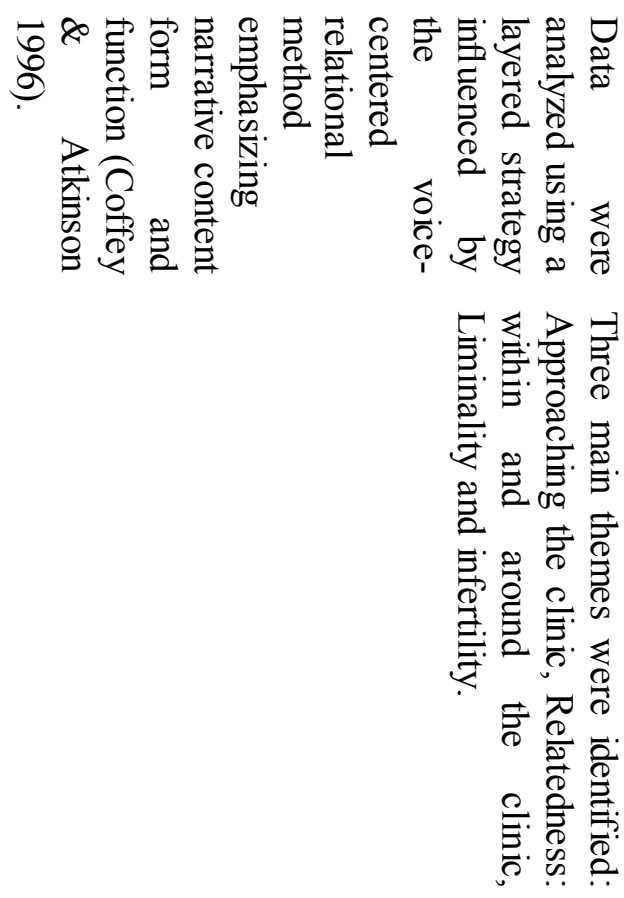


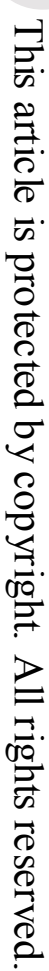

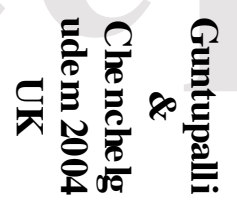

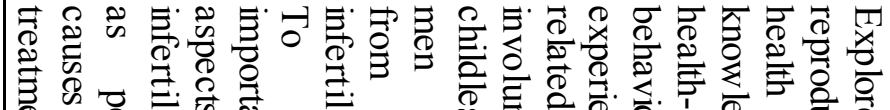

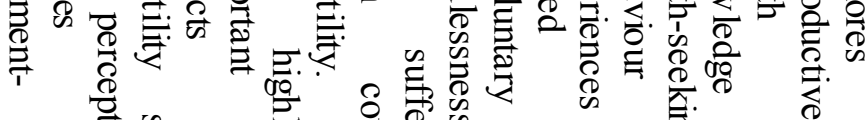

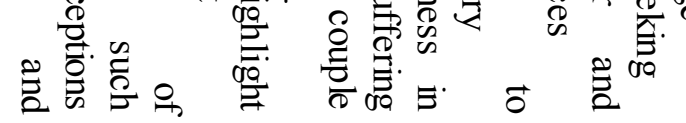

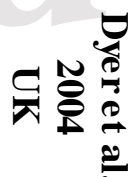

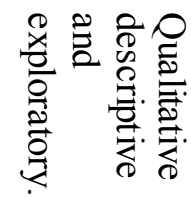

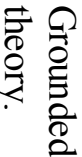

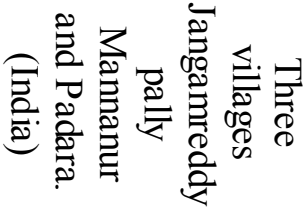

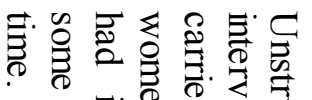

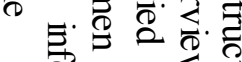

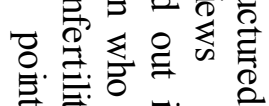

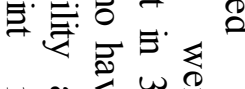

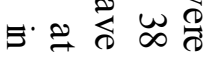

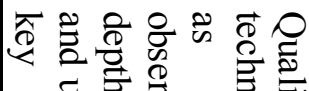

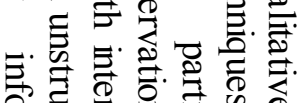

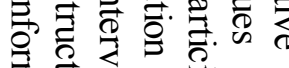

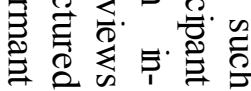

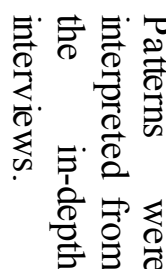

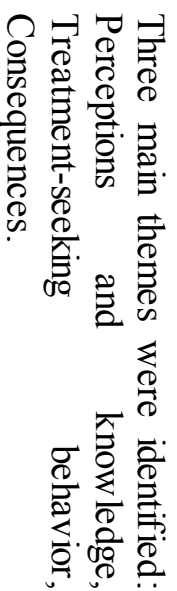

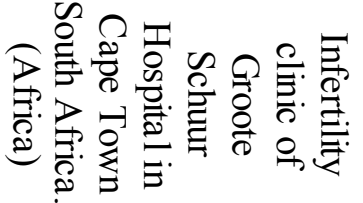

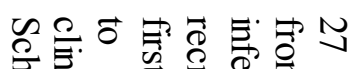

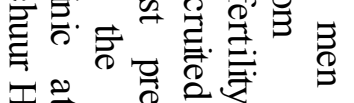

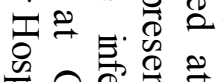

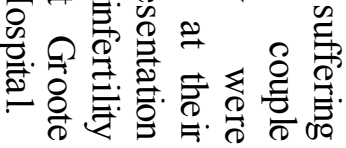

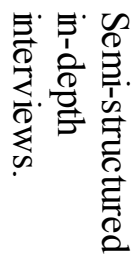

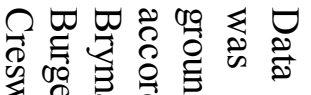

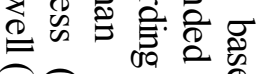

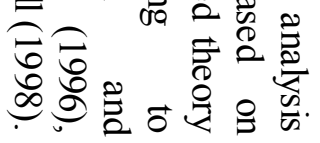

尺

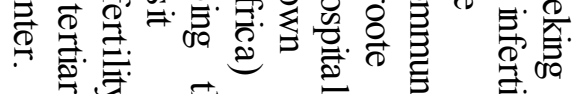

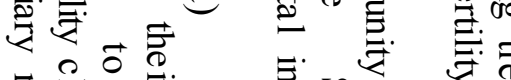

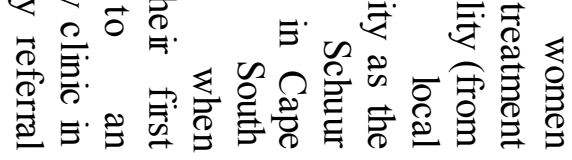

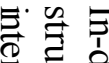

을. 을 $\sum_{\infty}^{\infty}$

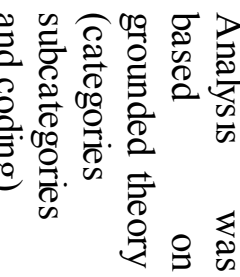

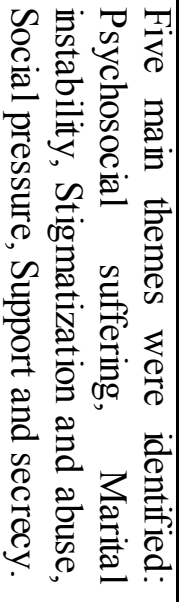




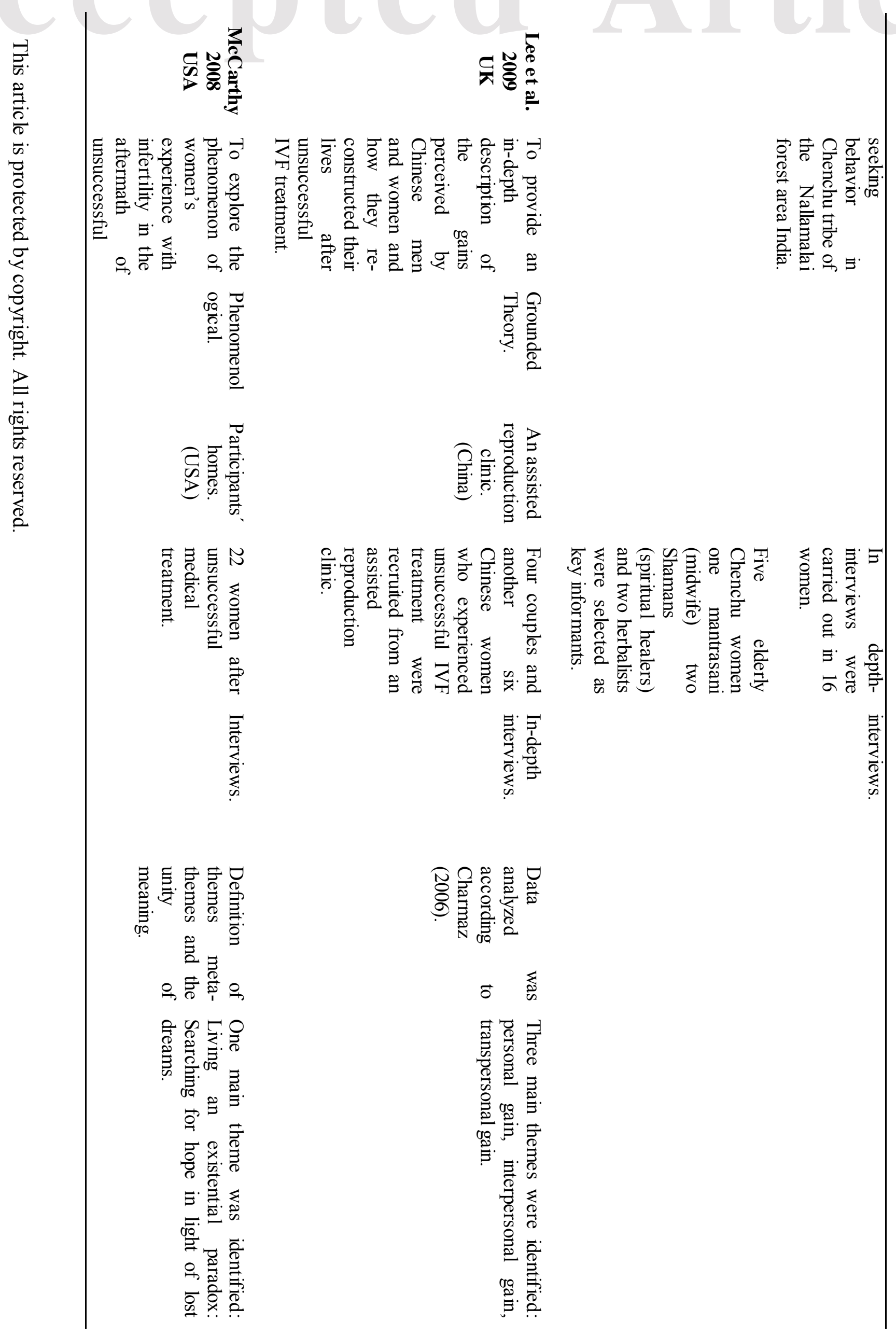




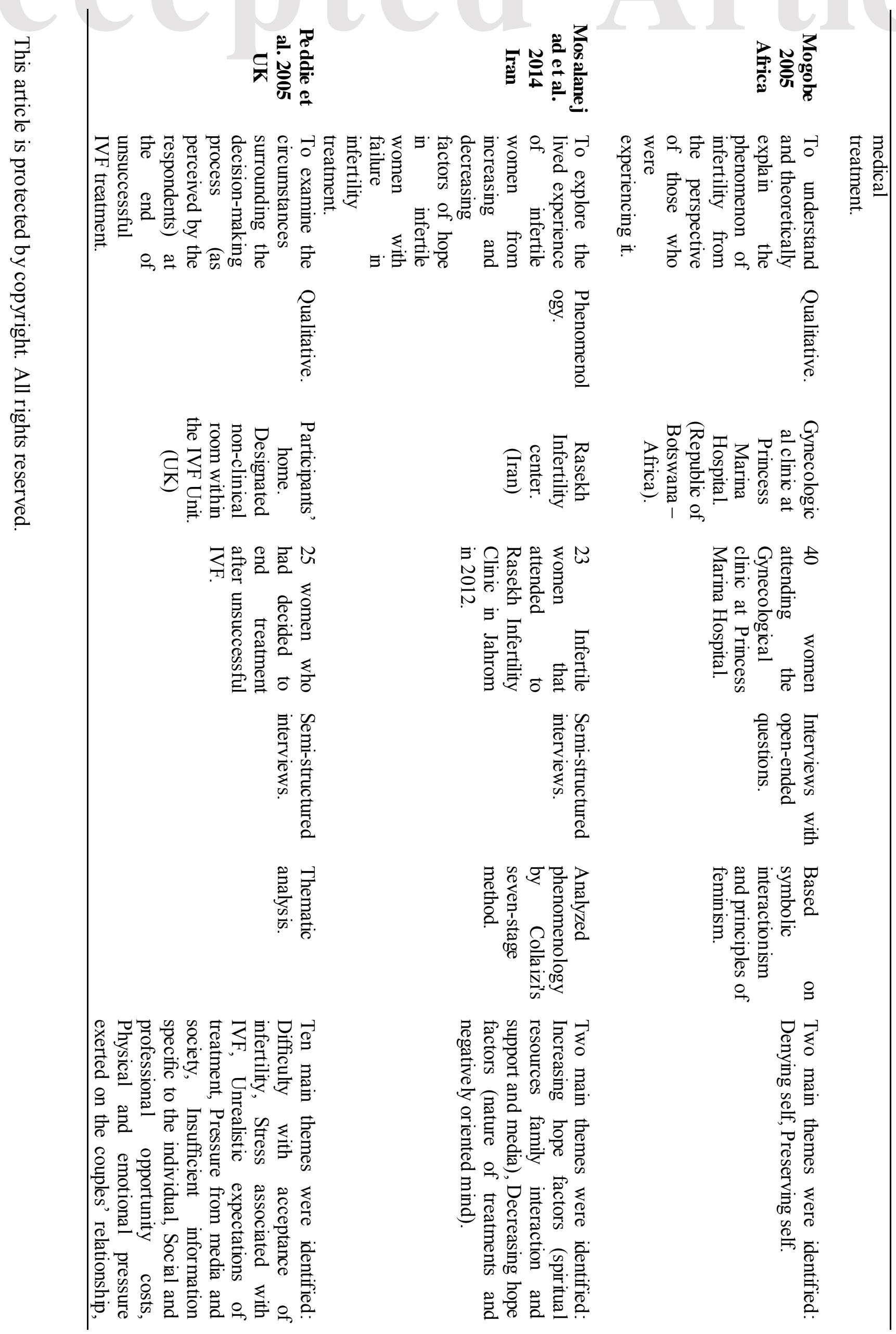




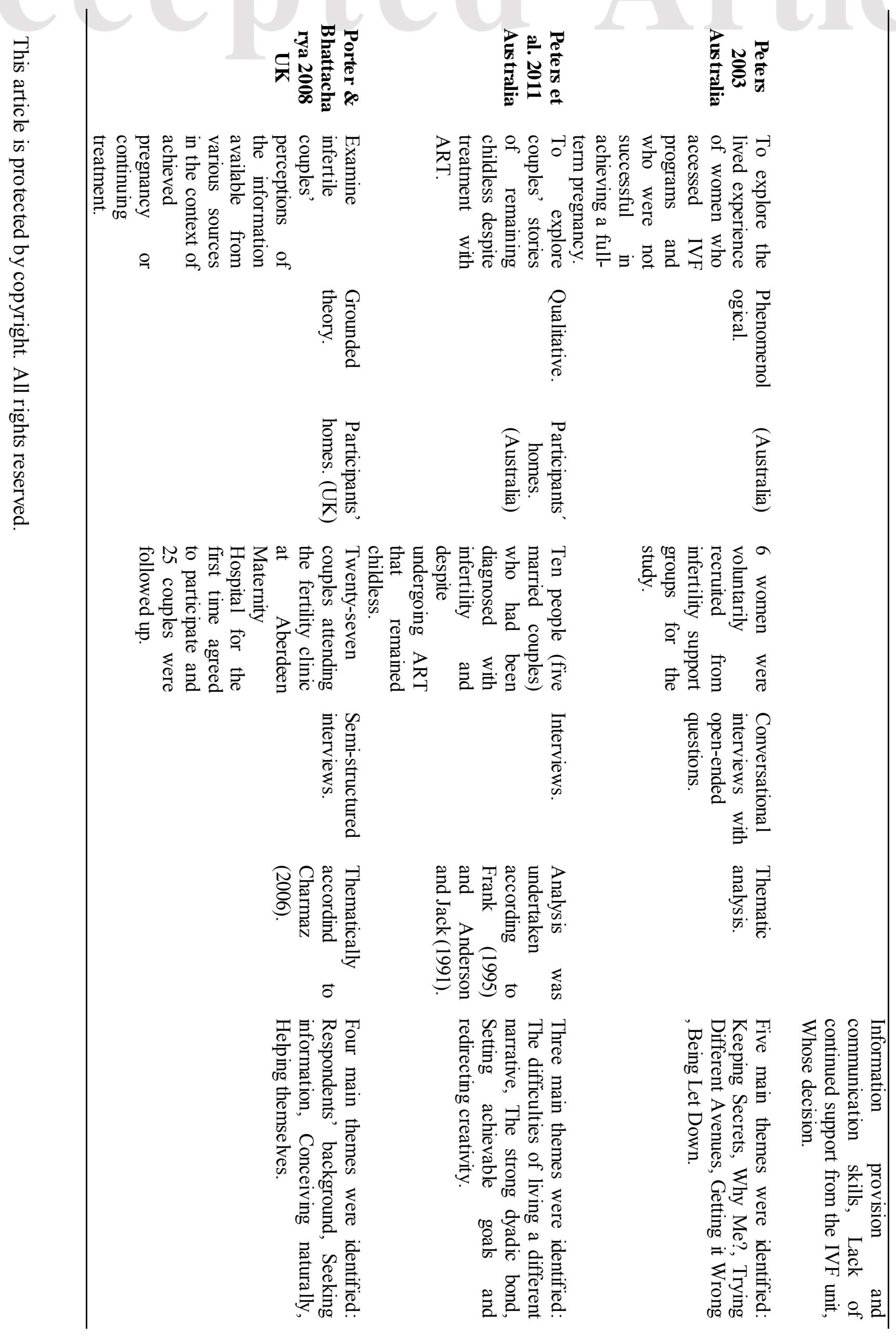




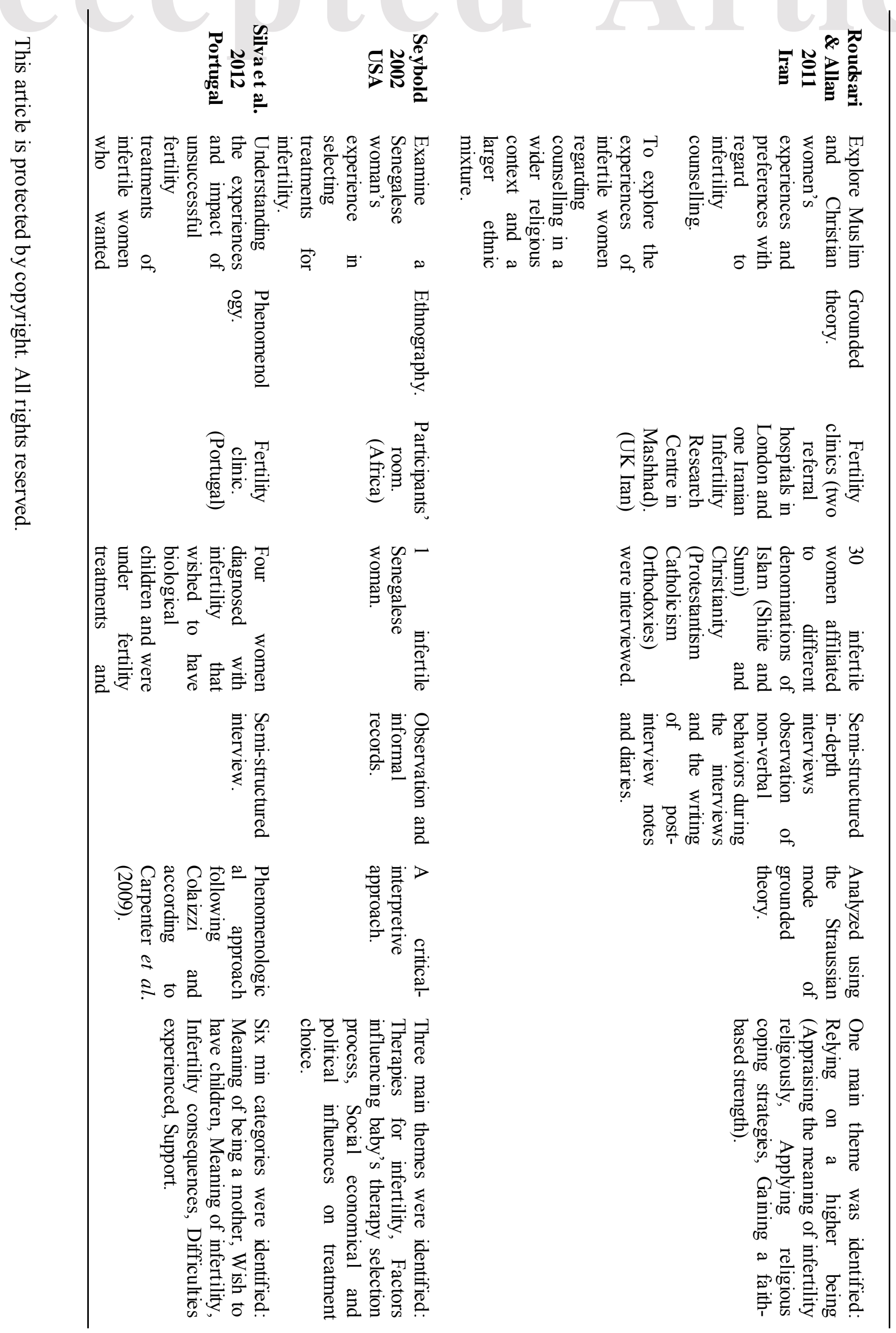




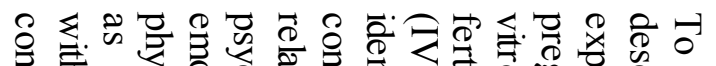

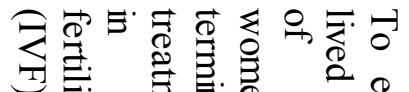

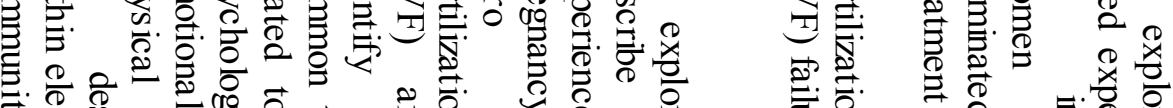

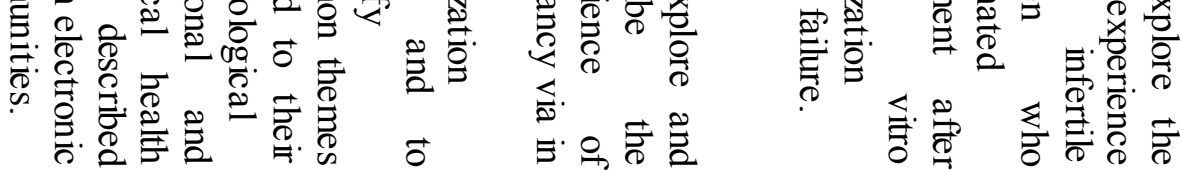

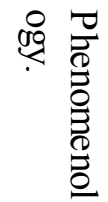

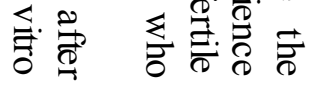

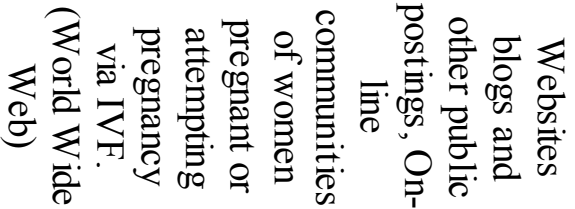

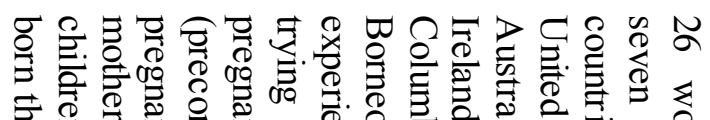

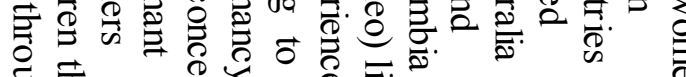

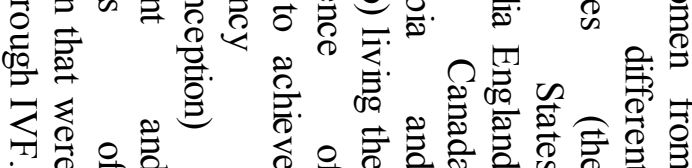

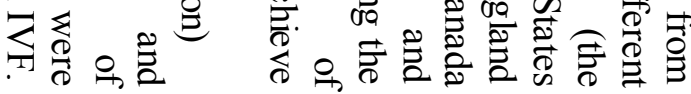

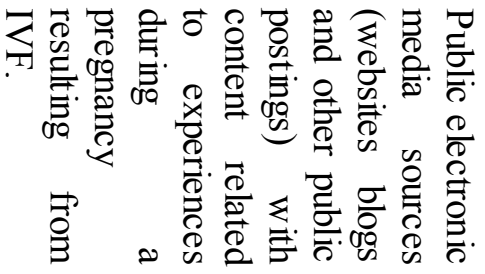

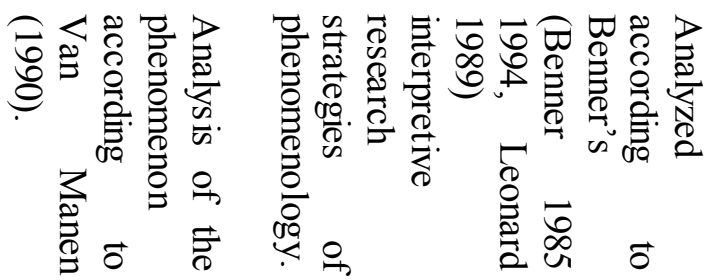

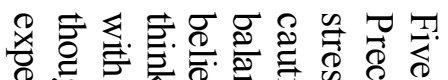

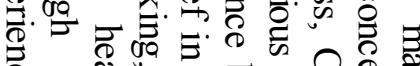
\&

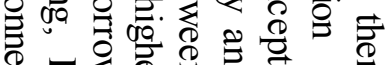

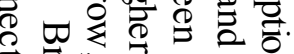

둥

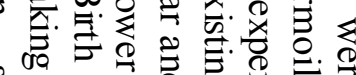
車 乙 น

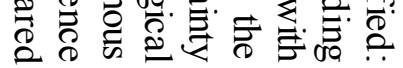

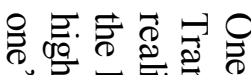

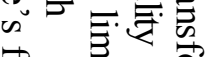

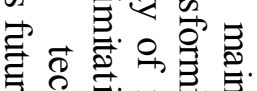

过苍.

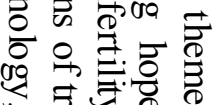

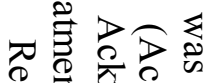

․ㅜㅇ. 응

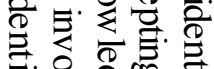

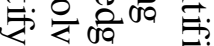

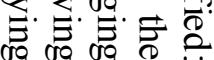

串高

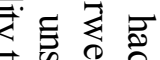

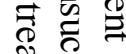

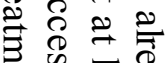
票蛋 $\frac{0}{\frac{0}{8}}$

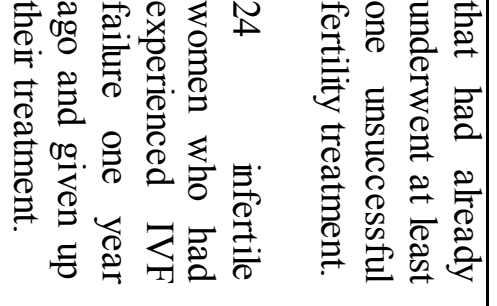




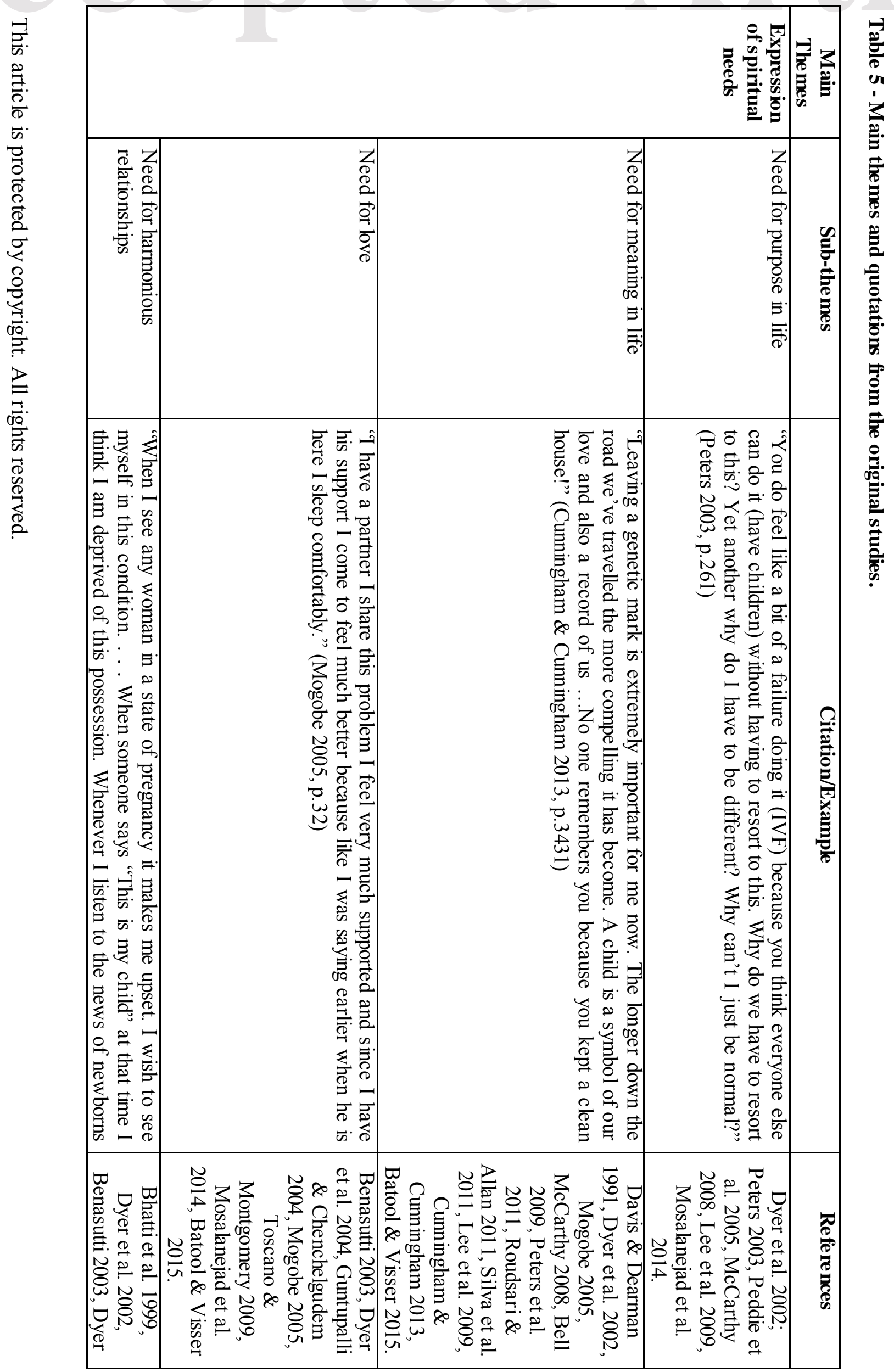




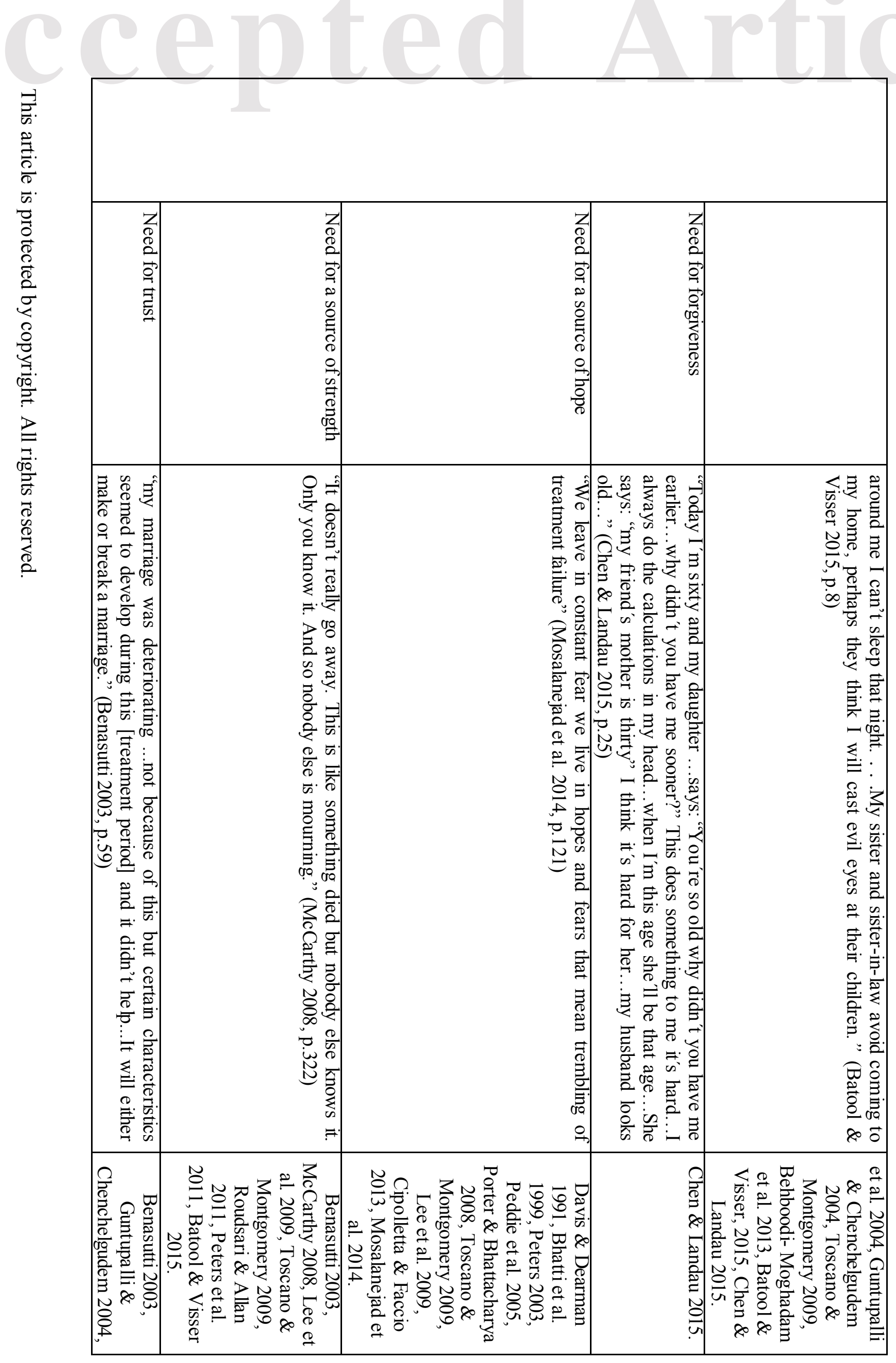




\begin{tabular}{|c|c|c|c|}
\hline 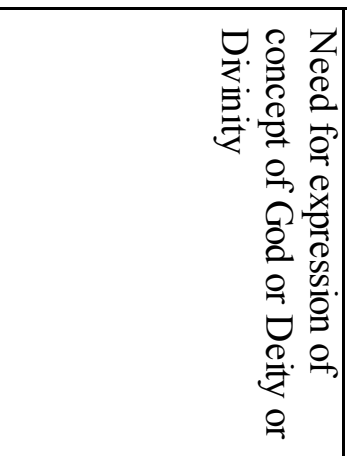 & 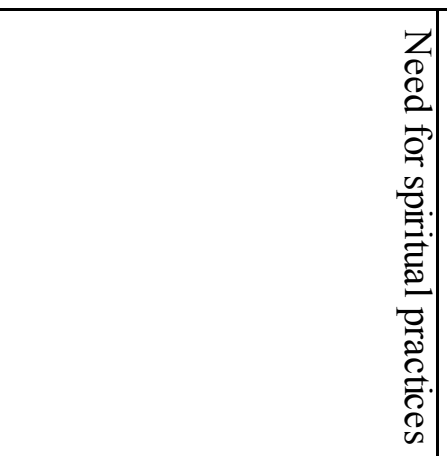 & 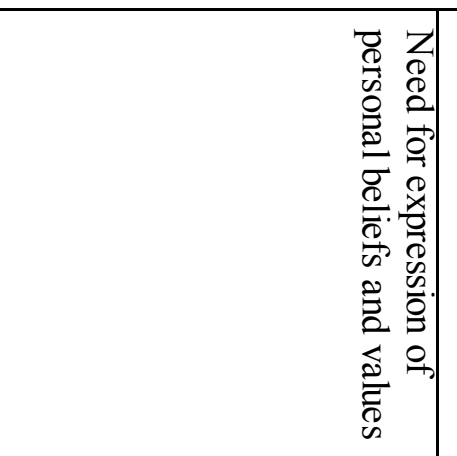 & \\
\hline 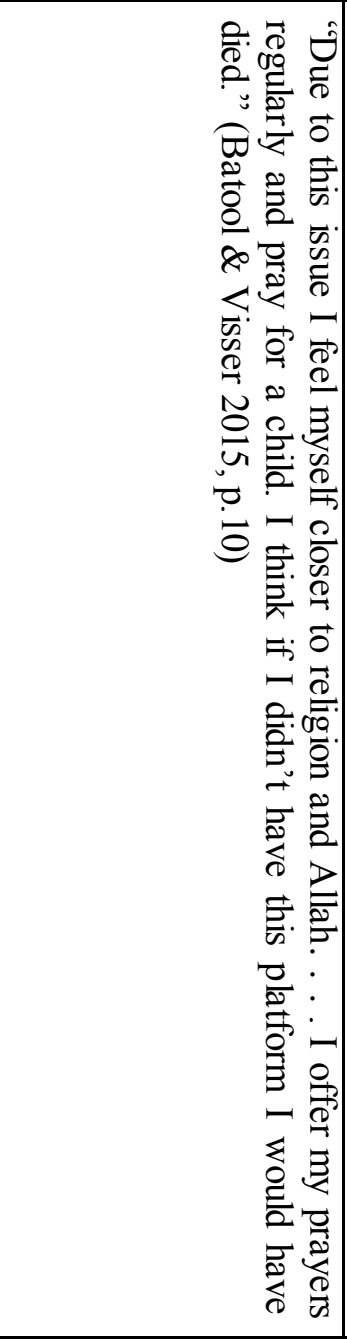 & 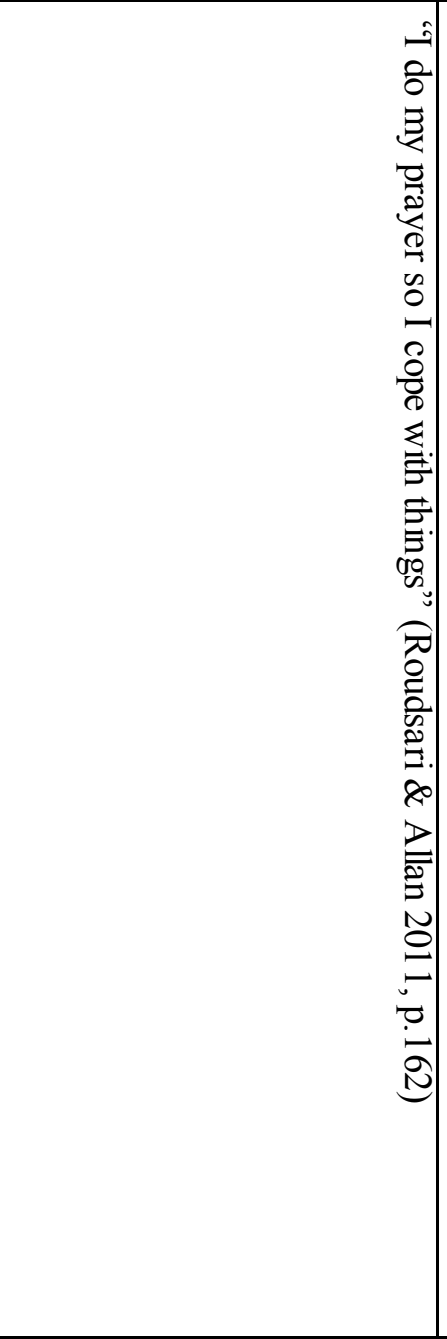 & 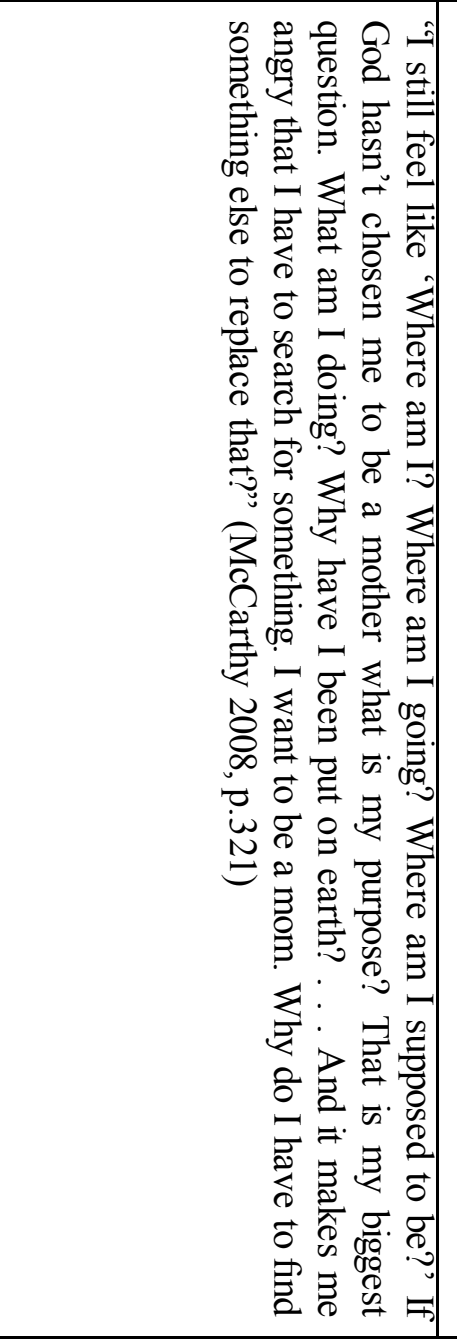 & \\
\hline 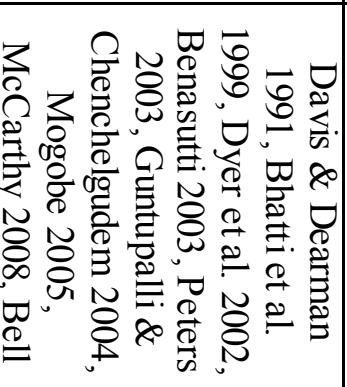 & 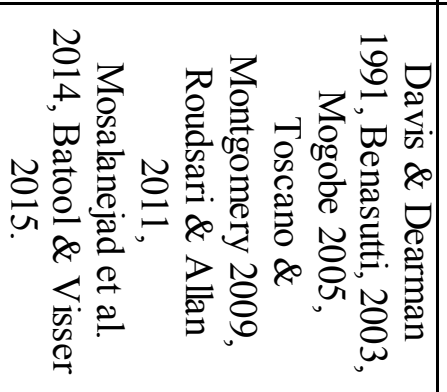 & 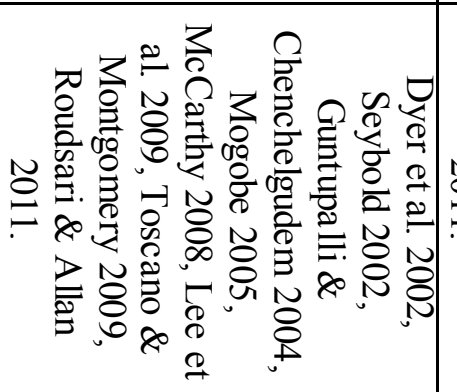 & 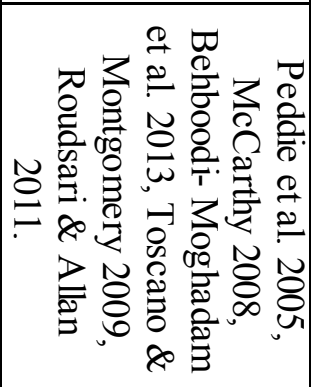 \\
\hline
\end{tabular}




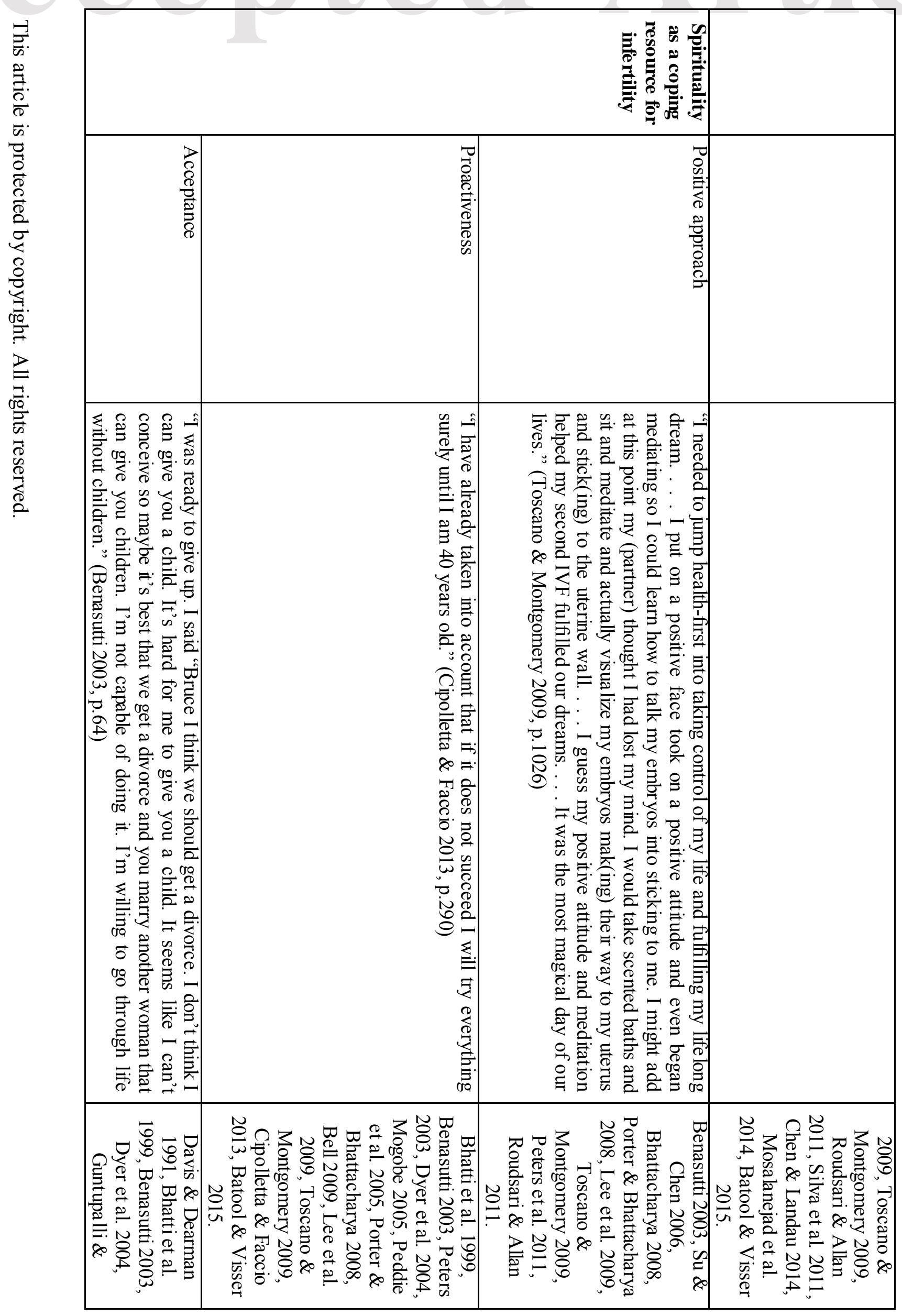




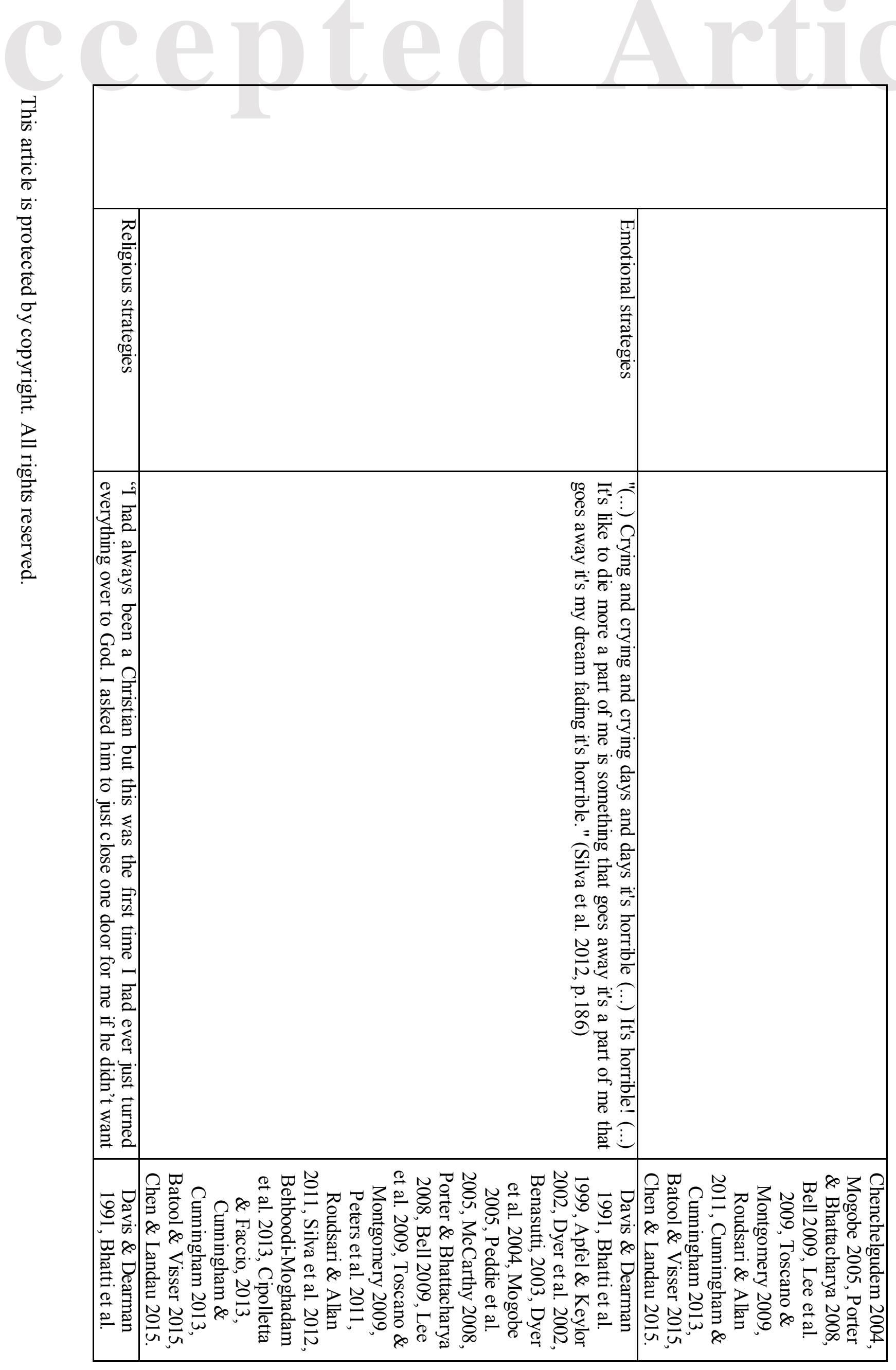




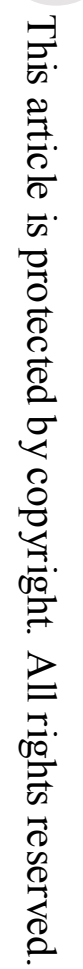

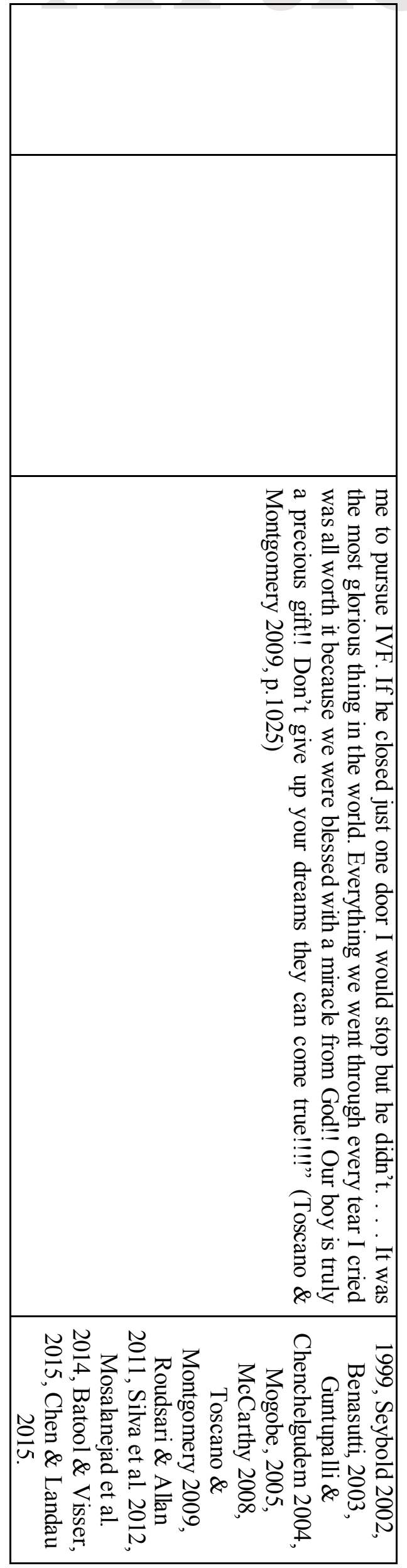

